\title{
Participation of women in doctorate, research, innovation, and management activities at Universidad Politécnica de Madrid: analysis of the decade 2006-2016
}

\author{
Estela Hernández-Martín ${ }^{1} \cdot$ Fernando Calle $^{1} \mathbb{D} \cdot$ Juan C. Dueñas $^{1} \mathbb{D D}^{\mathbb{D}} \cdot$ \\ Miguel Holgado ${ }^{1}$ (D) Asunción Gómez-Pérez ${ }^{1}$ [D
}

Received: 23 October 2018 / Published online: 11 July 2019

(c) Akadémiai Kiadó, Budapest, Hungary 2019

\begin{abstract}
This article studies the participation of women in doctorate, lecturing and research, innovation, and management activities at Universidad Politécnica de Madrid (UPM), the most important and largest university in Spain devoted to engineering and architecture. The analyses revealed significant differences in the ratio of male (76\%) and female (24\%) lecturing and research staff. This unequal ratio conducted to women underrepresentation in other actions such as coordination of international projects, decision-making designations, patenting and software licensing, collaboration with companies, and $\mathrm{PhD}$ supervision. $\mathrm{PhD}$ enrolment and $\mathrm{PhD}$ defence data, disaggregated by gender and by technological area, were also analysed as they are the starting point of the academic career, and showed a widespread male prevalence over women (ca. $70 \%$ men vs. $30 \%$ women). The aim of this paper is to present actual, accurate, objective, and gender-segregated information extracted from UPM databases, to carry out a qualitative study drawing on an opinion survey and a "gap" analysis, and to undertake a critical examination of the historic, political, sociocultural and personal factors affecting gender inequalities in academia. Policy recommendations to improve the situation of women and to achieve gender balance in the disciplines of engineering and architecture are also provided.
\end{abstract}

Keywords Research $\cdot$ Innovation $\cdot$ Doctorate $\cdot$ Management $\cdot$ Women $\cdot$ STEAM

Mathematics Subject Classification 62-07 · 62-09

JEL Classification I23 $\cdot$ I24 $\cdot$ J24 $\cdot$ J71 $\cdot$ N34 $\cdot$ O30

Electronic supplementary material The online version of this article (https://doi.org/10.1007/s1119 2-019-03179-9) contains supplementary material, which is available to authorized users.

Asunción Gómez-Pérez

vicerrector.investigacion@upm.es

1 Vice-Rectorate for Research, Innovation, and Doctoral Studies, Universidad Politécnica de Madrid, C/Ramiro de Maeztu 7, 28040 Madrid, Spain 


\section{Introduction}

The participation of women in scientific fields has attracted significant attention in the past years. Different reports have analysed the equality between men and women in the EU, studying the situation of women in different scenarios, such as tertiary education and executive jobs. Moreover, the adoption of anti-discriminatory measures, the discussion of equal treatment policies and women's rights was also well-documented in these papers (Lipinsky 2013; EC 2015, 2017).

In the particular case of Spain, former governments have published reports analysing the participation of the women in science and technology (MINECO 2011; Puy 2015). In the same line, the enrolment and the contribution of women in the engineering and architecture areas have been also widely documented (Pérez-Artieda et al. 2014), showing the prevalence of men over women in all the scenarios studied: undergraduates, $\mathrm{PhD}$ graduates, workforce, and decision-making positions. Nevertheless the gender gap in the field of engineering and architecture is especially significant and, although extensively literature has described the gender imbalance in science, has not been completely explored.

With these results, the European Research Area Vision set a clear goal for 2030: A greater presence of women in science and technology, when they state that "Half of all scientists and research policymakers, across all disciplines and at all levels of the science system, are women" (MINECO 2011). European institutions are then developing mandates and rules to apply gender mainstreaming and to eliminate gender inequalities as previously established in the Treaty of Amsterdam (1999) in the field of Science.

On an overall basis, women are underrepresented in STEAM (Science, Technology, Engineering, Architecture and Mathematics) areas. It is well known that there are several societal factors that contribute to the lower female participation, and these aspects are perfectly applicable to Spain, as described below (MINECO 2011; Nimmesgern 2016; Cheryan et al. 2017):

1. Gender stereotypes and discrimination, which are historically rooted in Spanish society.

2. Failure on the education on the basis of equality, combined with the media messages (television, videos, books, songs...): girls are usually expected to play a feminine role, while boys are educated for professional success.

3. Low rates of female students in STEAM degree programs (bachelor, master and doctorate), as young girls do not express interest in these fields as boys do.

4. Lack of knowledge of engineering, technology and physics since the early ages, due to the small implementation of these subjects in the school curriculum, whereas other disciplines are widely considered.

5. Gender gaps in perceived self-efficacy and self-confidence in engineering topics.

6. Family formation and personal factors, as female engineers and scientists with children find more difficult to re-enter into the workforce after a period of absence, such as maternity leave or family care.

7. Labour market, public bodies and institutions, and its policies.

This inequality is reflected not only in a lower rate of female employment but also in a lesser wage, in accordance to the data provided by the Spanish Statistical Institute. ${ }^{1}$

1 www.ine.es/en/welcome.shtml. 
Moreover, only $10 \%$ of the Spanish companies have achieved gender balance in their management committee, according to the Gender Monitor of ESADE Business School (2016).

Apart from these global aspects, many studies attribute the gender gap to a lack of female role models (Herrmann et al. 2016) and female mentoring (Meschitti and Smith 2017) in STEAM areas, which are considered "male" topics, while Social Sciences and Arts are primarily "female" ones, thus contributing to the prevalence of the men in technological areas.

Generally speaking, the persistent lack of female participation in research activities at UPM could be attributed to several deeply-rooted historic and societal factors. To begin with, gender equality plans and guidelines to promote the incorporation of women into the labour market and the higher education were introduced at Spanish workplaces and universities in the late 1980s, mostly due to the social circumstances prevailing under former governing regimes. Public investment in universities also increased in the 1980s, attributable to the entry into force of the Spanish law LRU (Ley Orgánica 11/1983 de Reforma Universitaria). This law aimed to establish a framework for the renewal of academic life and to reform the university education, which resulted in a considerable growth in job opportunities for $\mathrm{PhD}$ graduates, habitually men in those times (Villarroya et al. 2008; Albert et al. 2016a). At the same time, female lecturing and research staff around the 50 years of age, that is, those who concentrate the higher project incomes and lead "top" UPM research groups, as described in the following sections, were starting or about to start their degrees in the mid-80s.

Nevertheless, and as observed in the statistical data presented in this study, gender bias is still deep-seated in Spanish universities and public research bodies in part because of the historical late entry of women into higher education (Ovseiko et al. 2016), and hence doctorate and academic positions.

According to Vázquez-Cupeiro and Elston (2006), "Despite recent measures to reform the recruitment patterns in Spanish universities towards a more meritocratic model, the tradition of a "Sistema endogámico" (an "inbreeding”system) persists, under which appointments are frequently made on the basis of internal (departmental) networks". This closed model was expected to disfavour women when applying for a tenured position, as men were majority.

As breakpoint and opposed to the aforementioned "inbreeding" system, the Spanish legislative reform LOU (Ley Orgánica 6/2001 de Universidades) of 2001 promoted open, transparent and merit-based selection procedures in academia. This law intended to avoid biased recruitment and to implement a national system to assess the merits of the individual applicants (scientific performance, teaching and educational experience, secondments and stays in international research institutions, participation in innovation activities, mentoring and $\mathrm{PhD}$ advising, etc.). On the other hand, the Spanish law 3/2007 (Ley Orgánica para la igualdad efectiva de mujeres y hombres) marked a turning point in effective equality of women and men, as it aimed to prevent discriminatory behaviors and to provide the active policies to enforce the principle of equality. This implied a projection of the gender mainstreaming over the social, cultural and artistic scopes, in which inequality could be generated or perpetuated, considering the equality as a cross-sectional issue. As a result, the entry into force of these measures had a positive, although lower than expected, effect over the years, contributing to the slight increase of the proportion of women holding a permanent position in UPM (Zufiaurre et al. 2010).

As female engineers act as role models in the society and they might motivate a deep change in the engineering schools, the present work raises the question: What are the 
situation, the position and the contribution of female lecturing and research staff in engineering and architecture universities?

To answer these demands, this paper analyses the participation of women in doctorate, research, innovation, and management activities, over the past 10 years, at Universidad Politécnica de Madrid (UPM), the largest and most senior Spanish university in engineering and architecture. This study is focused on the research productivity, the academic career and the professional development of women belonging to UPM. The progress and the variations observed in terms of time were monitored and compared, and a critical review of the sociocultural factors affecting gender inequalities in academia was also carried out. A deeper qualitative study (opinion survey) was conducted to unveil the mechanisms that affect gender equality. Moreover, policy recommendations to achieve gender balance in STEAM are presented in this paper.

Answers to key questions will be provided throughout this study: How the percentage of women has changed, or not, in the last decade? Are women more involved than men in innovation activities? Who takes more time in completing a doctoral degree, men or women? Have women a higher success rate of grant proposals than men? What is the ratio of women who coordinate European projects? Are female $\mathrm{PhD}$ advisors relatable role models? Do the researchers perceive discrimination in UPM? Do the working conditions reconcile between family and professional life? What are the main causes of the underrepresentation of women in UPM? How is the career path at UPM?

\section{Methodology}

\section{Information sources}

Data was extracted from UPM internal software $S 2 i, A G O R A$ and APOLO, which are described below.

$S 2 i$ (Research Management System) is employed to manage data related to research and innovation projects at UPM. As a general database, it contains information about the following topics:

1. Research projects: call, funding entity, coordinator, participants, budget, area, scope, and description.

2. Research staff: personal data, position, research group, projects, research productivity, and teaching.

3. Research structures: including names, data and productivity of engineering schools, departments, research centres, institutes, and groups.

4. Exploitation of results: patents and trademarks, licenses, software, know-how, UPM companies, spin-offs, and start-ups.

AGORA is a computer system capable of streamlining the management of academic data, including $\mathrm{PhD}$ studies at UPM, offering information about personal data of $\mathrm{PhD}$ students and their advisors, and information of the $\mathrm{PhD}$ programme enrolment (number of years, doctoral programme, affiliation, etc.). This ERP (Enterprise Resource Planning) is part of the commercial software "Universitas XXI" elaborated by the company OCU (Office for University Cooperation). 
APOLO is a database containing comprehensive records of the $\mathrm{PhD}$ theses defended at UPM from 1980 onwards. It includes the following information:

1. $\mathrm{PhD}$ theses: title, area, doctoral programme, research plan, and assessments on a yearly basis.

2. Scientific information of the PhD candidate and his/her advisor(s): curriculum, filiation, scientific output (publications, participation in conferences, research projects, etc.)

3. PhD defence: thesis committee, approval and authorisation for defence.

These three databases fulfil a strict and systematic quality control, ensuring the accuracy and veracity of the information. With these records, a detailed analysis of the participation of women in doctorate, research, innovation, and management activities at UPM was carried out.

\section{UPM data collection, data analysis and graphical methods}

Information gathered from $S 2 i$, is outlined hereafter: (1) Research and management data (from 2007 to 2016); (2) Innovation data (from 2007 to 2016); and iii) Postdoctoral researchers records (from 2007 to 2015). Whereas $\mathrm{PhD}$ enrolment data (from 2007 to 2015) and $\mathrm{PhD}$ thesis advisors information (from 2006 to 2016) were collected from AGORA, PhD theses records were extracted from APOLO (from 2007 to 2015).

The present study was performed amongst the finite population of lecturing and research staff, $\mathrm{PhD}$ undergraduates, postdoctoral researchers and $\mathrm{PhD}$ theses at UPM. The number of elements of the population was fixed, consisting of each and every element of the entire group. Thus statistical inference was not employed, but descriptive statistics of the population. The census or complete enumeration was possible due to the records kept in the internal databases.

Results were depicted as percentages of the data processing, by gender (female/male); the sample size (total, $n$ ), by gender, was also represented in the graphs for more clarity (histogram), ensuring that this parameter was large enough to obtain reliable and representative insights.

Tables 1, 2, 3, 4 and 5 show the total number of data studied ( $n$ total), covering the last decade, and disaggregated by gender. The average value for the time range analysed $(<n>$ and $\langle \%\rangle$ ) and the standard deviation (SD) were also calculated.

\section{Opinion survey and "gap" analysis}

An online, voluntary, survey was sent to all UPM researchers $(n=4350)$. The diagnostic phase was completed on 23 February 2018. They belonged to one of the following research professional categories: pre-doctoral researchers (R1), post-doctoral and temporary researchers (R2), tenured professors (R3), and full professors (R4). 672 researchers answered the survey obtaining a $15 \%$ rate of response. Measurements were made with an uncertainty of less than or equal to $3.48 \%$ at the $95 \%$ confidence level, with a realistic worst-case scenario $(p=q)$.

The survey asked for input, degree of implementation and comments regarding the 40 principles of the European Charter \& Code of Conduct for the Recruitment of 
Table 1 PhD students covering the period 2007-2015, by Engineering and Architecture area and by gender

\begin{tabular}{|c|c|c|c|c|}
\hline & & $n$ Total & $<n>(\mathrm{SD})$ & $<\%>(\mathrm{SD})$ \\
\hline \multicolumn{5}{|l|}{ PhD students' first registration } \\
\hline \multirow[t]{2}{*}{ UPM } & Male & 9419 & $942(152)$ & $67(2)$ \\
\hline & Female & 4588 & $459(91)$ & $33(2)$ \\
\hline \multirow[t]{2}{*}{ ICTs } & Male & 2219 & $222(40)$ & $77(3)$ \\
\hline & Female & 661 & $66(14)$ & $33(3)$ \\
\hline \multirow[t]{2}{*}{ Agroforestry and environmental technologies } & Male & 1124 & $112(26)$ & $60(5)$ \\
\hline & Female & 733 & $73(17)$ & $40(5)$ \\
\hline \multirow[t]{2}{*}{ Industrial technologies } & Male & 2409 & $241(38)$ & $76(8)$ \\
\hline & Female & 805 & $81(34)$ & $24(8)$ \\
\hline \multirow[t]{2}{*}{ Civil and building technologies } & Male & 3376 & $338(116)$ & $60(3)$ \\
\hline & Female & 2214 & $221(66)$ & $40(3)$ \\
\hline \multirow[t]{2}{*}{ Other technologies } & Male & 286 & $36(6)$ & $64(6)$ \\
\hline & Female & 166 & $21(6)$ & $36(6)$ \\
\hline \multicolumn{5}{|l|}{ PhD defence } \\
\hline \multirow[t]{2}{*}{ UPM } & Male & 2213 & $221(134)$ & $71(2)$ \\
\hline & Female & 936 & $94(69)$ & $29(2)$ \\
\hline \multirow[t]{2}{*}{ ICTs } & Male & 536 & $51(21)$ & $79(5)$ \\
\hline & Female & 154 & $14(6)$ & $21(5)$ \\
\hline \multirow[t]{2}{*}{ Agroforestry and environmental technologies } & Male & 364 & $36(12)$ & $61(7)$ \\
\hline & Female & 243 & $24(13)$ & $39(7)$ \\
\hline \multirow[t]{2}{*}{ Industrial technologies } & Male & 564 & $56(34)$ & $77(7)$ \\
\hline & Female & 168 & $17(10)$ & $23(7)$ \\
\hline \multirow[t]{2}{*}{ Civil and building technologies } & Male & 698 & $70(65)$ & $70(5)$ \\
\hline & Female & 349 & $35(42)$ & $30(5)$ \\
\hline \multirow[t]{2}{*}{ Other technologies } & Male & 41 & $6(6)$ & $44(29)$ \\
\hline & Female & 29 & $4(2)$ & $56(29)$ \\
\hline
\end{tabular}

$n$ total, population; $\langle n>$ and $<\%>$, mean values; $\mathrm{SD}$, standard deviation

Table $2 \mathrm{PhD}$ advisors and postdoctoral researchers covering the period 2006-2016 and 20072015 , respectively, by gender

\begin{tabular}{lccc}
\hline & $n$ total & $<n>(\mathrm{SD})$ & $<\%>(\mathrm{SD})$ \\
\hline PhD advisors & & & \\
$\quad$ Male & 3258 & $296(139)$ & $90(1)$ \\
Female & 388 & $35(22)$ & $10(1)$ \\
Postdoctoral researchers & & & \\
Male & 169 & $19(8)$ & $76(9)$ \\
Female & 60 & $7(5)$ & $24(9)$ \\
\hline
\end{tabular}

$n$ total, population; $\langle n>$ and $<\%>$, mean values; $\mathrm{SD}$, standard deviation

Researchers, ${ }^{2}$ and requested to explain why a principle was not implemented. Additionally, the survey asked the participants to evaluate the importance of each of the 40 principles.

$\overline{2}$ https://euraxess.ec.europa.eu/sites/default/files/am509774cee_en_e4.pdf. 
Table 3 Lecturing and research staff covering the period 2007-2016, by engineering and architecture area and by gender

\begin{tabular}{lccc}
\hline PDI & $n$ total & $\langle n\rangle$ (SD) & $<\%>(\mathrm{SD})$ \\
\hline UPM & & & \\
$\quad$ Male & 25,508 & $2251(138)$ & $76(1)$ \\
$\quad$ Female & 8021 & $802(33)$ & $24(1)$ \\
ICTs & & & \\
$\quad$ Male & 5764 & $576(24)$ & $78(0.5)$ \\
$\quad$ Female & 1627 & $163(4)$ & $22(0.5)$ \\
Agroforestry and environmental & & & \\
$\quad$ technologies & & & \\
$\quad$ Male & 3573 & $357(33)$ & $66(2)$ \\
$\quad$ Female & 1817 & $182(8)$ & $34(2)$ \\
Industrial technologies & & & \\
$\quad$ Male & 7744 & $774(35)$ & $81(1)$ \\
$\quad$ Female & 1853 & $185(9)$ & $19(1)$ \\
Civil and building technologies & & & \\
$\quad$ Male & 7627 & $763(49)$ & $76(2)$ \\
$\quad$ Female & 2410 & $241(18)$ & $24(2)$ \\
Other technologies & & & \\
$\quad$ Male & 627 & $63(3)$ & $73(4)$ \\
Female & 234 & $23(4)$ & $23(4)$ \\
\hline
\end{tabular}

PDI, Personal Docente e Investigador, Lecturing and Research Staff; $n$ total, population; $\langle n>$ and $<\%>$, mean values; SD, standard deviation

\begin{tabular}{lrrr}
\hline PDI & $\mathrm{n}$ total & $\langle n>(\mathrm{SD})$ & $<\%>(\mathrm{SD})$ \\
\hline International proposals presented* & & & \\
$\quad$ Male & 1929 & $193(36)$ & $76(4)$ \\
$\quad$ Female & 625 & $63(20)$ & $24(4)$ \\
Awarded international projects* & & & \\
$\quad$ Male & 526 & $53(3)$ & $76(4)$ \\
$\quad$ Female & 162 & $16(7)$ & $2(4)$ \\
National proposals presented** & & & \\
$\quad$ Male & 639 & $160(20)$ & $79(2)$ \\
$\quad$ Female & 295 & $43(3)$ & $21(2)$ \\
Awarded national projects** & & & \\
$\quad$ Male & 173 & $74(22)$ & $81(3)$ \\
$\quad$ Female & 69 & $17(3)$ & $19(3)$ \\
Principal investigators*** & & & \\
$\quad$ Male & 1472 & $164(6)$ & $84(2)$ \\
Female & 280 & $31(4)$ & $16(2)$ \\
\hline
\end{tabular}

PDI, Personal Docente e Investigador, Lecturing and Research Staff; $n$ total, population; $\langle n\rangle$ and $\langle \%\rangle$, mean values; SD, standard deviation *2007-2016; **2013-2016; ***2008-2016 
Table 5 Participation in innovation activities, covering the period 2007-2016, by Engineering and Architecture area and by gender

\begin{tabular}{llrcc}
\hline & PDI & $n$ total & $\langle n\rangle(\mathrm{SD})$ & $<\%>(\mathrm{SD})$ \\
\hline Patents & & & & \\
UPM & Male & 1052 & $105(28)$ & $89(4)$ \\
& Female & 116 & $12(2)$ & $11(4)$ \\
ICTs & Male & 289 & $29(13)$ & $90(10)$ \\
& Female & 34 & $3(3)$ & $10(10)$ \\
Industrial Tech. & Male & 540 & $54(18)$ & $94(2)$ \\
& Female & 31 & $3(1)$ & $6(2)$ \\
Civil and Building Tech. & Male & 172 & $17(9)$ & $83(10)$ \\
& Female & 32 & $3(3)$ & $17(10)$ \\
Software licenses & & & & \\
UPM & Male & 261 & $26(12)$ & $71(14)$ \\
& Female & 94 & $9(5)$ & $29(14)$ \\
ICTs & Male & 170 & $17(9)$ & $69(19)$ \\
& Female & 70 & $7(6)$ & $31(19)$ \\
University-Industry Chairs & & & & \\
UPM & Male & 1672 & $167(15)$ & $85(1)$ \\
& Female & 291 & $29(5)$ & $15(1)$ \\
\hline & & & &
\end{tabular}

PDI, Personal Docente e Investigador, Lecturing and Research Staff; $n$ total, population; $\langle n\rangle$ and $<\%>$, mean values; $\mathrm{SD}$, standard deviation

Average score was also calculated for each one (how much the researchers consider the principles are implemented and their importance).

The questions to answer are described below:

1. Level of implementation "To what extent does UPM meet this principle?" (Fully implemented/Almost but not fully implemented/Partially implemented/Insufficiently implemented/No answer-Don't know)

2. "In the case that you consider that the criteria is not fully implemented, please indicate the actual "gap" between the principle and the current practice in UPM".

3. "Initiatives undertaken and/or suggestions for improvement".

4. Importance "On scale of 1-4, how unimportant (1) or important (4) is for you the implementation of this principle at UPM?".

However, only those principles regarding with gender balance, equal opportunities, recruitment, working conditions and career advancement were considered for this research.

\section{Technological areas}

UPM schools and activities have been traditionally encompassed into the following five technological areas:

1. Information and Communication Technologies (ICTs): Computer Science and Telecommunications Engineering. 
2. Agroforestry and Environmental Technologies: Agricultural, Food and Biosystems; and Forestry and Natural Resources Engineering.

3. Industrial Technologies: Industrial, Aeronautics and Space, Naval Architecture and Marine, Mining and Energy Engineering.

4. Civil and Building Technologies: Architecture; Building; Civil; Land Surveying, Geodesy and Mapping Engineering.

5. Other Technologies: Sciences for Physical Activity and Sports, and Fashion Design.

Some analyses were carried out disaggregating UPM raw data into these areas, when it was representative, to provide accurate information by gender as a function of the engineering area.

\section{Results}

This section is structured into two main parts. First, we will review the details of the participation of women in the activities of doctorate, lecturing and research, innovation, and management in UPM; these data are merely descriptive. Second, an opinion survey amongst all UPM researchers will allow to enable the main causes of the low participation of women.

\section{Statistical analyses}

\section{Doctorate: PhD enrolment and defence, PhD supervision, and postdoctoral activities}

Generally speaking, the proportion of $\mathrm{PhD}$ students and $\mathrm{PhD}$ graduates in Spanish universities is gender-balanced ( $50 \%$ women vs. $50 \%$ men, and $51 \%$ women vs. $49 \%$ women, respectively, for the academic course 2016-2017), according to the data provided by the Ministry of Education and Vocational Training. ${ }^{3}$ On the contrary, Fig. 1a shows a widespread male prevalence over women in the third cycle (doctorate studies) at UPM. In other words, the vast majority of the students that started doctoral studies and completed a $\mathrm{PhD}$ were men (30\% women vs. $70 \%$ men, and $33 \%$ women vs. $67 \%$ men, respectively), whereas it is true that the proportion of female $\mathrm{PhD}$ candidates was higher compared to female lecturing and research staff (see Fig. 5a).

For the analysis, we have taken into account that the ratio of students for a particular academic year has an impact in the proportion of $\mathrm{PhD}$ theses defended 4 or 5 years after $\mathrm{PhD}$ enrolment, bearing in mind the average time to complete a $\mathrm{PhD}$ degree in UPM (4.57 years for men, 4.86 years for women). Although women take a longer time to complete their $\mathrm{PhD}$ theses than men, their success rate is higher (30\% female students enrolled vs. $33 \% \mathrm{PhD}$ theses defended by women).

Besides, the entry into force of the Spanish law which actually governs official doctoral studies (RD 99/2011) caused a marked increase in the number of $\mathrm{PhD}$ theses defended before the previous regulations were extinguished (see Fig. 1b, showing $889 \mathrm{PhD}$ theses in academic course 2015-2016). Another consequence of RD 99/2011 was the reduction of the thesis duration (3 years), which may affect differently to men and women.

However, in these subjects of study dealing with $\mathrm{PhD}$ degree (both $\mathrm{PhD}$ enrolment and $\mathrm{PhD}$ defence), it was necessary to look beyond the overall data of UPM to discern the situation in each of the five engineering and architecture areas. According to Fig. 2a

${ }^{3}$ http://www.mecd.gob.es/portada-mecd/. 
Fig. 1 Doctoral studies at UPM, by gender: a PhD students' first registration; and $\mathbf{b} \mathrm{PhD}$ defence. Filled triangle, Men (\%); filled square, Women (\%); line square, Men (n); dotted square, Women (n); 2007 refers to academic course 2007-2008
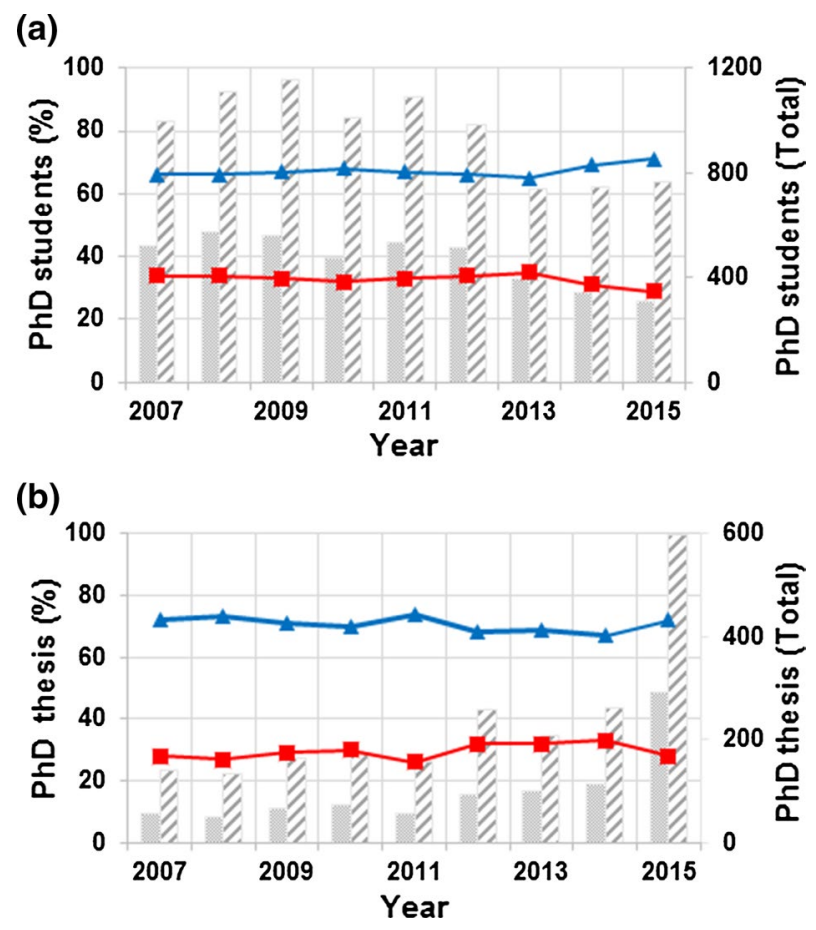

and b, in ICTs, which comprised 11 Doctoral Programmes, the proportion of female $\mathrm{PhD}$ students decreased slightly from 2012 onwards, which meant a reduction in the $\mathrm{PhD}$ theses defended by women from 2015. Further investigation in the most representative ICT schools (Computer Science and Telecommunication Engineering), concluded that the average percentage of women that started doctoral studies and completed a $\mathrm{PhD}$ barely reached $25 \%$ in all cases.

Agroforestry and Environmental Technologies included chemical and biological approaches in all the eight Doctoral Programmes offered, which are topics with, traditionally, a greater representation of women (Cheryan et al. 2017). The percentage of new female PhD students experienced a steady increase from 2007 to 2012, when a break point was registered after achieving gender balance, followed by a dramatic decrease (Fig. 2c). Likewise, gender balance in $\mathrm{PhD}$ theses defended was reached from 2013 onwards (Fig. 2d), although the proportion of $\mathrm{PhD}$ theses defended by women belonging to Agricultural, Food and Biosystems Engineering Doctoral Programmes showed a continued decline from 2014 onwards.

When dealing with Industrial Technologies, which comprised 13 Doctoral Programmes, there has been a dramatic decline in the proportion of women/men enrolled from 2007 $(43 / 57, \%)$ to $2010(17 / 83, \%)$, followed by a slight increase from 2011 onwards (average 21/79, \%), as depicted in Fig. 2e. The ratio of $\mathrm{PhD}$ theses defended in the period 2010-2014 did not appear to be in line with the ratio of women enrolled in the period 2007-2010, which might lead to the conclusion that a marked percentage of women dropped out from doctoral studies before $\mathrm{PhD}$ completion (Fig. 2f). The schools with a lower participation of women were those devoted to Aeronautic and Naval Engineering, both with $12 \%$ female 
$\mathrm{PhD}$ students, and $12 \%$ and $6 \%$ female $\mathrm{PhD}$ graduated, respectively, on average from academic year 2007-2008 onwards.

In evaluating Civil and Building Technologies and their 11 Doctoral Programmes, the number of women enrolled in PhD studies raised from 2007 (36/64, \%) to 2012 (44/56, $\%$ ), and then experienced a significant decrease, as shown in Fig. $2 \mathrm{~g}$. As a consequence of this, a growing trend in the women awarded with a $\mathrm{PhD}$ was observed in Fig. $2 \mathrm{~h}$ (38/62, \%, in 2015). A deeper analysis of the most representative schools, indicated that Architecture showed the same tendency. Nevertheless, a "steady state" in Civil Engineering, from 2012 onwards, especially in $\mathrm{PhD}$ enrolment was achieved (ca. 30/70, \%).

Finally, Other Technologies comprised two Doctoral Programmes. Figure 2i gathered data from the Faculty of Sciences for Physical Activity and Sports, and the School of Fashion Design. The latter offered the new doctoral programme "Architecture, Design, Fashion, and Society" from the academic course 2016-2017 onwards, having a positive effect on the number of women enrolled in $\mathrm{PhD}$ studies for this area (data not represented). Moreover the mean value of $\mathrm{PhD}$ theses defended was $56 \%$ for women, covering the period 2009-2015.

On the other hand, Fig. 3 displays the percentage of $\mathrm{PhD}$ thesis advisors at UPM, by gender, where the lack of relatable feminine role models became evident (Meschitti and Smith 2017). Female $\mathrm{PhD}$ supervisors only represented $10 \%$ on average for the period 2006-2016. This figure was much less than the average proportion of women in research and lecturing staff (24\%) and in doctoral studies (30\%), which indicated that female $\mathrm{PhD}$ students were mostly matched with a male $\mathrm{PhD}$ advisor.

When revising the situation of the postdoctoral researchers hired by UPM within the framework of the most outstanding human resources programmes, the main tendency was the male prevalence over women, as depicted in Fig. 4. To simplify the analysis, competitive Spanish actions "Ramón y Cajal" and "Juan de la Cierva", as well as Marie Skłodowska-Curie Individual Fellowships (EU call), were considered. These are regarded as major academic achievements and may give access to a tenured-track position in Spanish universities. Whereas in 2007 gender balance was not far away (36\% female and 64\% male), the average percentage of women in years 2012-2015 dropped significantly to $23 \%$, which was considerably lower than the average ratio of women that were awarded with a PhD Degree at UPM (33\%).

\section{Research activities: lecturing and research staff, and research projects}

As a starting point and according to the data provided by the Observatorio $\mathrm{I}+\mathrm{D}+\mathrm{i} \mathrm{UPM}$ Unit, from the Vice-Rectorate for Quality and Efficiency, the overall percentage of female lecturing and research staff was $26 \%$ in 2016, and this figure raised from $22 \%$ to $26 \%$ in the period 2006-2016. On the other hand, the average ratios of female administrative and services staff and female students was $49 \%$ and $32 \%$, respectively, over the same period.

Figure 5 depicts the evolution over the past 10 years (2007-2016) of the lecturing and research staff, holding a permanent contract with UPM, such as full professors, tenured professors, assistant professors, and equivalent positions. The overall underrepresentation of women in all UPM (see Fig. 5a) was stubborn and had a negative impact in further topics and areas of this study, although there was a small increase in the proportion of women/ men from $2010(23 / 77, \%)$ to $2016(26 / 74, \%)$. 
(a)

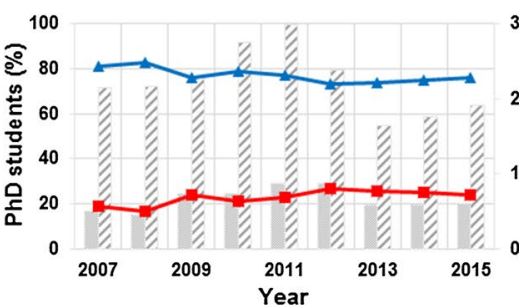

(c)

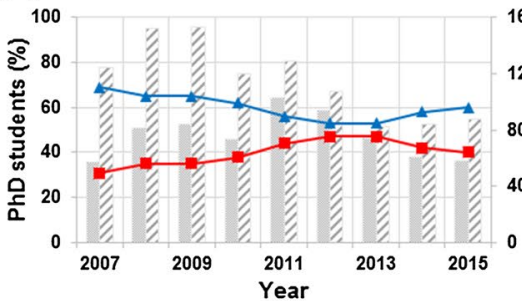

(e)

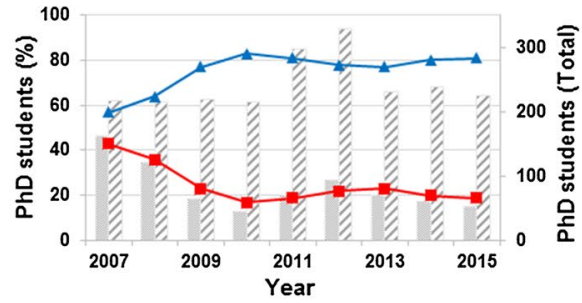

(g)

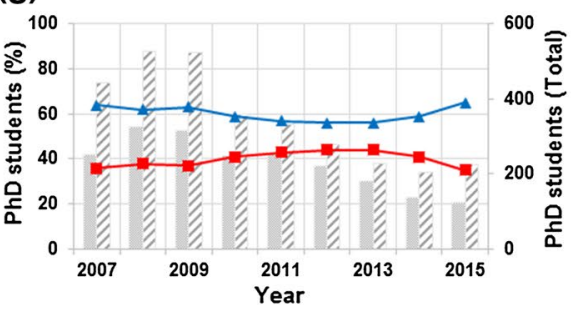

(i)

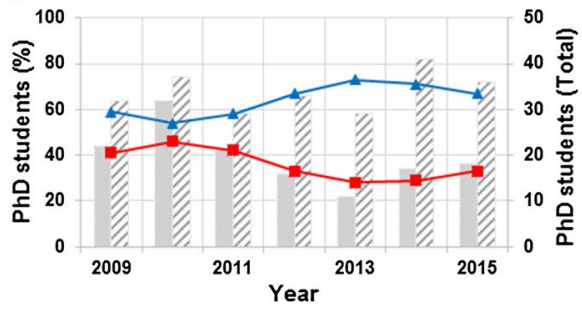

(b)
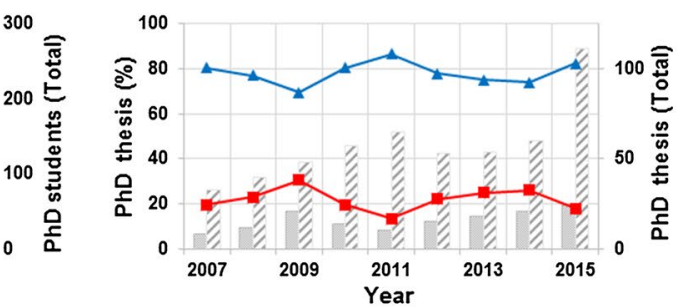

(d)

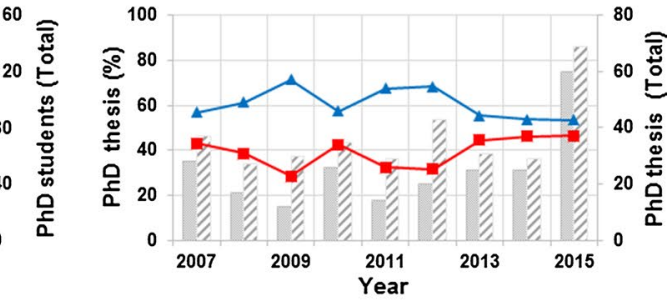

(f)

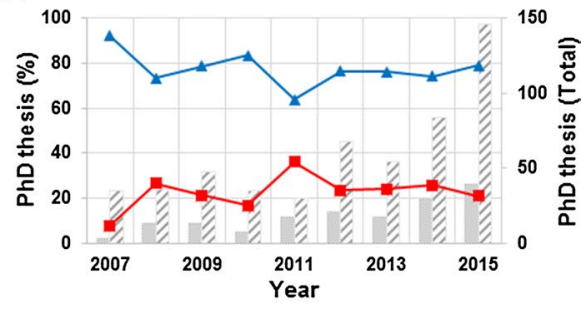

(h)

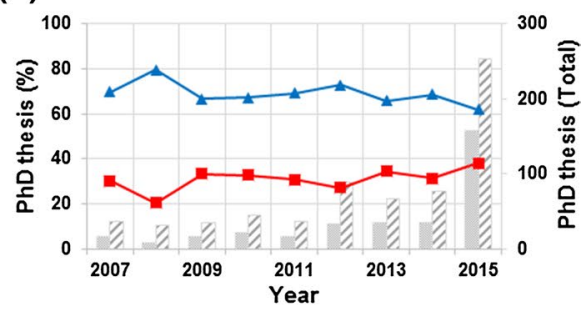

(j)

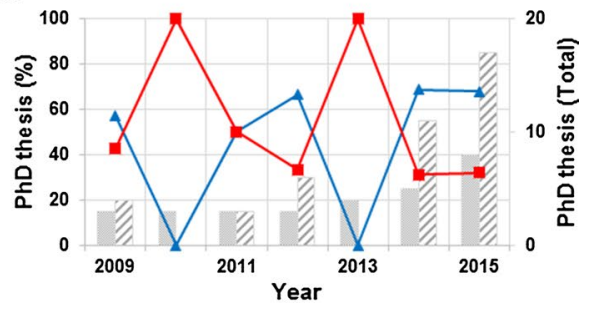


4 Fig. 2 PhD students' first registration and PhD defence at UPM, by technological area and by gender: a ICTs PhD students' first registration; b ICTs PhD theses defended; c Agroforestry and Environmental Technologies $\mathrm{PhD}$ students' first registration; d Agroforestry and Environmental Technologies PhD theses defended; e Industrial Technologies PhD students' first registration; f Industrial Technologies PhD theses defended; g Civil and Building Technologies PhD students' first registration; h Civil and Building Technologies PhD theses defended; i Other Technologies PhD students' first registration; and j Other Technologies $\mathrm{PhD}$ theses defended. Filled triangle, Men (\%); filled square, Women (\%); line square, Men $(n)$; dotted square, Women $(n) ; 2007$ refers to academic course 2007-2008

Fig. $3 \mathrm{PhD}$ thesis advisors at UPM, by gender. Filled triangle, Men (\%); filled square, Women $(\%)$; line square, Men $(n)$; dotted square, Women $(n) ; 2007$ refers to academic course 2007-2008

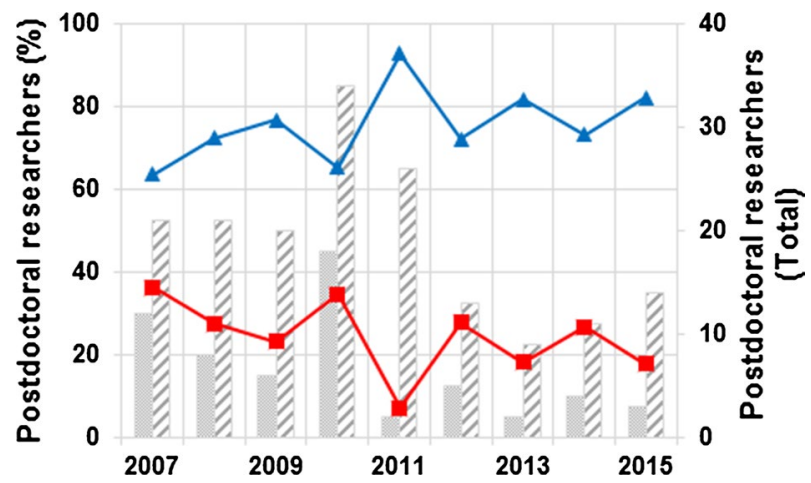

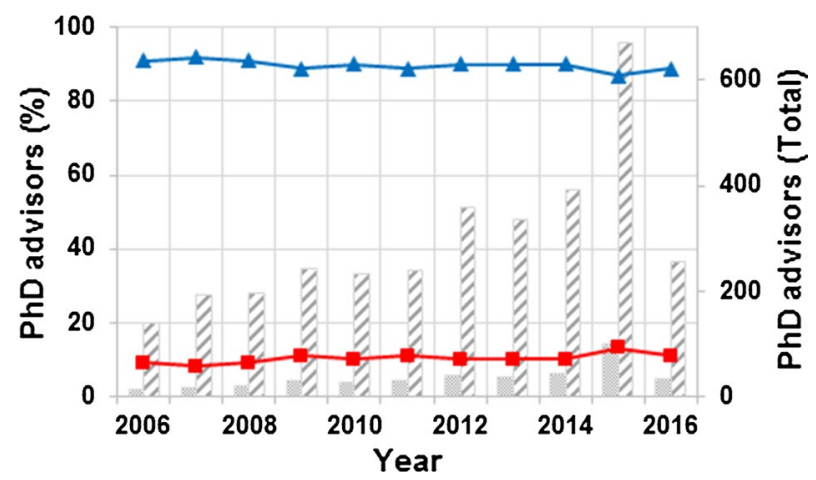

$\frac{2}{\frac{9}{a}}$
Fig. 4 Post-doctoral researchers at UPM, by gender. Filled triangle, Men (\%); filled square, Women (\%); line square, Men $(n)$; dotted square, Women $(n)$; 2007 refers to the year's call

Figure 5b displays the proportion of female/male lecturing and research staff for ICTs. The percentage of women seemed to have reached a steady-state over the years regardless of the number of teachers recruited (22\% on average).

On the other hand, Fig. 5c, Agroforestry and Environmental Technologies, showed the highest percentage of women, as well as a continuous growth in 2011-2016 year range (from 33/67 to $37 / 63, \%$ ).

Industrial Technologies was the area with the lower representation of female lecturing and research staff (see Fig. 5d), with a proportion of only $19 \%$ women on average. It is worth mentioning the constant, although still low, increase in the female participation achieved from 2007 (18/82, \%) to $2016(21 / 79, \%)$.

A higher growth in the ratio of women was found in Civil and Building Technologies (Fig. 5e), which increased progressively from $22 \%$ (2007) to $27 \%$ (2016). 
(a)

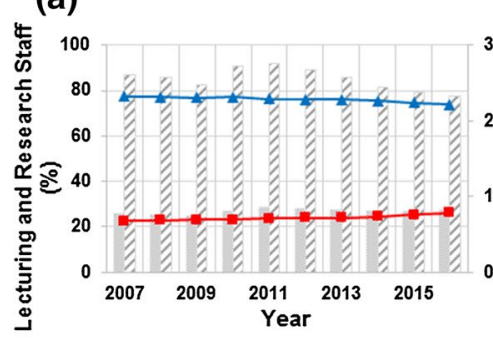

(c)

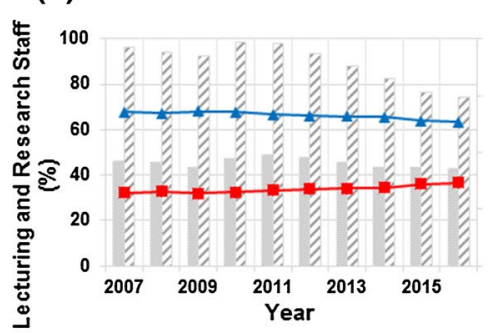

(e)

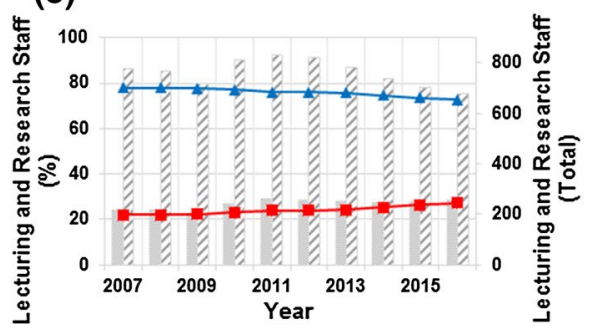

(b)

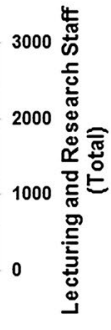

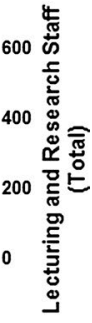

(d)
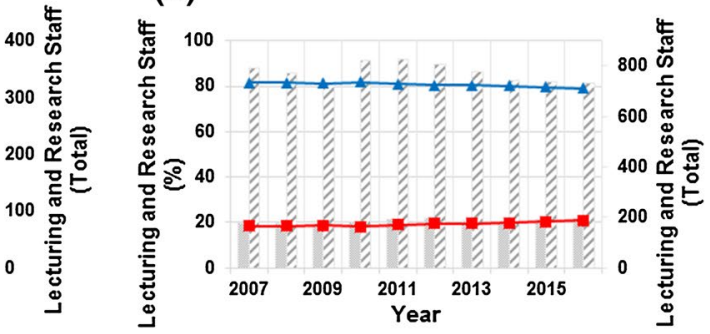

\section{(f)}

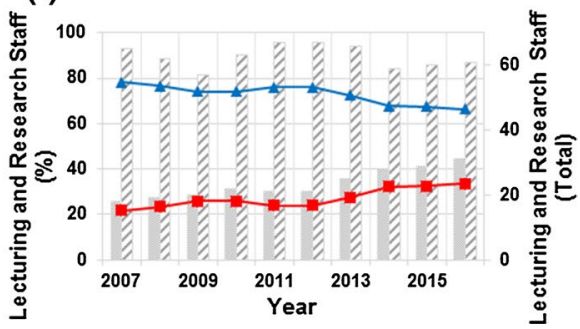

Fig. 5 Evolution of the lecturing and research staff at UPM, by gender and areas: a UPM; b ICTs; c Agroforestry and Environmental Technologies; d Industrial Technologies; e Civil and Building Technologies; and $\mathbf{f}$ Other Technologies. Filled triangle, Men (\%); filled square, Women (\%); line square, Men $(n)$; dotted square, Women $(n)$

The situation of women belonging to Other Technologies deserved special mention (see Fig. 5f), since the female proportion experimented a very significant increase from 2012 (24\%) to $2016(34 \%)$.

Figure 6 shows the participation of women as coordinators in projects. Figure 6 a depicts the proposals presented in international calls, whereas Fig. 6b represents the awarded international projects. Actions funded under Seventh Framework Programme (FP7) and Horizon 2020 (H2020), both EU Research and Innovation programmes, represented the major part of the incomes. But other EU actions (COST and Interreg) as well as international calls funded by the European Space Agency (ESA) and the Ibero-American Development Program for Science and Technology (CYTED, Programa Iberoamericano de Ciencia y Tecnología para el Desarrollo) were also taken into consideration for analysis. The average success rate in 2007-2016 year range was 28\%, varying from a minimum $19 \%$ in 2014 (attributed to the serious impact of the financial crisis) to a maximum 34\% in 2008 and 2016 (coinciding with pre-crisis and post-crisis influence periods). A deeper analysis 
Fig. 6 Projects at UPM, by gender: a International proposals presented; b Awarded international projects; c National proposals presented; and d Awarded national projects. Filled triangle, Men (\%); filled square, Women $(\%)$; line square, Men $(n)$; dotted square, Women $(n) ; 2007$ refers to the year's call (a)

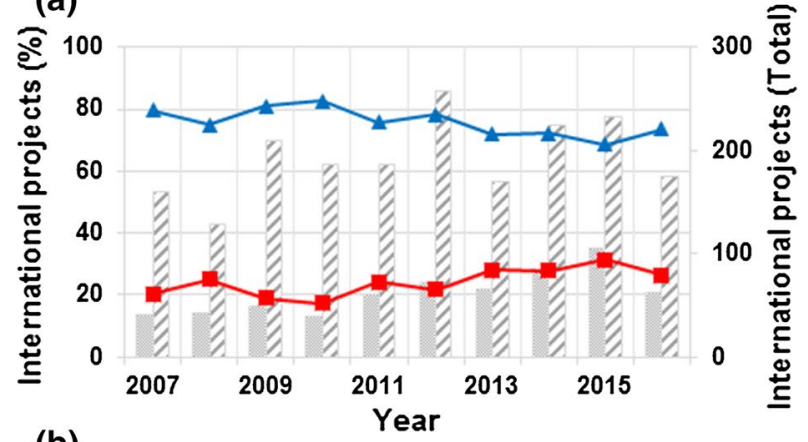

(b)

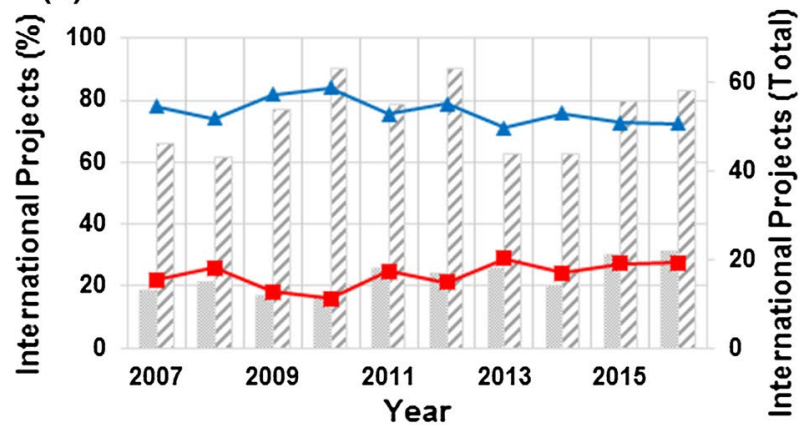

(c)

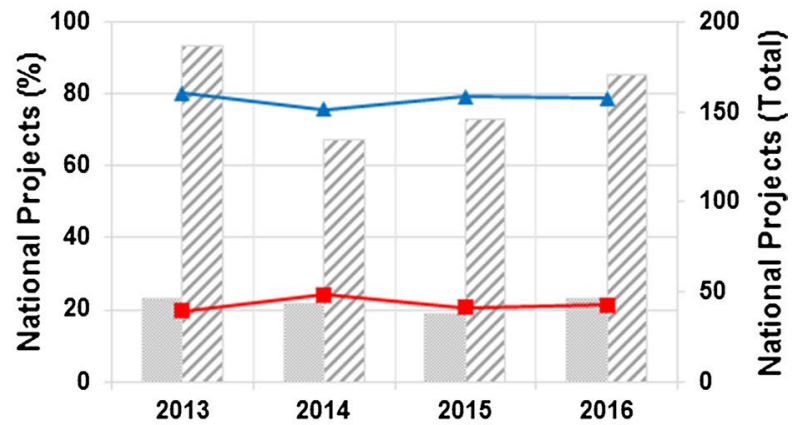

(d)

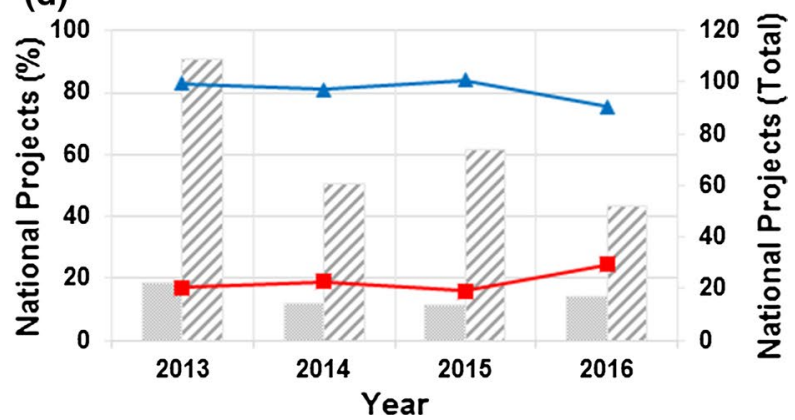


revealed that both graphs displayed a similar trend, where the average ratio of women was $27 \%$ for presented proposals and $28 \%$ for granted projects from 2013 onwards. This phenomenon indicated that gender-biased evaluation of proposals was negligible within the framework of the projects analyzed. No significant differences were found in the average success rate of granted projects covering the period 2007-2016: $26 \%$ for women and $27 \%$ for men.

The participation of women as project leaders in the Spanish National Plan for Scientific and Technical Research and Innovation is depicted in Fig. $6 \mathrm{c}$ and d. In this case, S2i database only registered records from 2013 onwards. The mean value for presented proposals was $21 \%$ women versus $79 \%$ men. The average ratio for granted projects was $19 \%$ women versus $81 \%$ men, although a sharp increase for projects headed by women was reached in 2016 (25\%). It should be pointed out that the average success rate for awarded projects was $39 \%$ for women versus $46 \%$ for men, covering the period 2013-2016, tentatively suggesting that the evaluation was gender-biased.

These findings were complemented by those shown in Fig. 7, which depicts the accumulated budget in international projects led by women, for the period 2007-2016, as a function of their age. The highest concentration of incomes converged in the 47-53 age group, with the exception of researchers aged 65 (10 M€), making a total of 35 women. This tendency was determined by the fact that these middle-aged female researchers were mostly full or tenured professors (31\% and 43\%, respectively, in 2017) with a long professional career, excellent records and scientific production. They also headed consolidated groups, mainly belonging to ICTs (34\%) and Agroforestry and Environmental Technologies (26\%). It is also worth noting that $34 \%$ of these women (12 out of 35 ) work in research lines dealing with chemical and biological approaches (Bioengineering, Telemedicine, etc.). Further analysis revealed that 27 out of 35 of these female researchers were awarded with their first project at the average age of 42 years old $(49 \%$ of them were in the age range 41-43 years old). They also collaborated with recognized international groups and companies, in fact the majority (57\%) has spent time

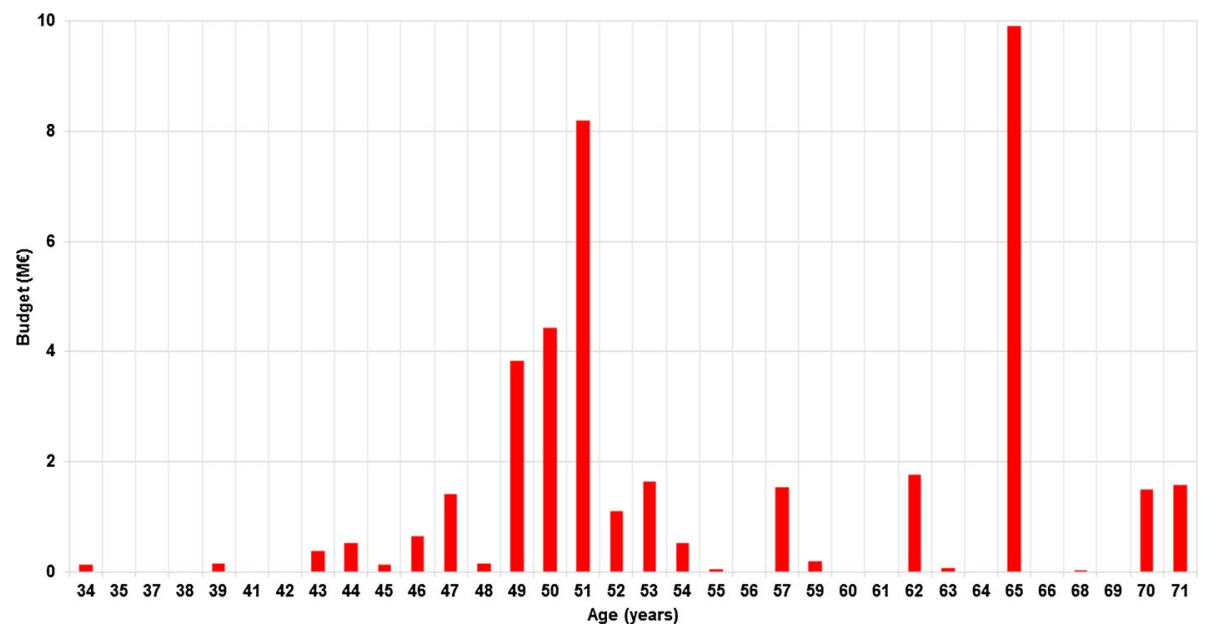

Fig. 7 International projects leaded by women at UPM: Accumulated budget (year's call from 2007 to 2016) as a function of the age 
at research and development centres abroad (international secondments and research stays).

The mean value of women as international projects coordinators was $27 \%$ in the period 2007-2016, ranging from $9 \%$ in 2009 to 50\% in 2013. From 2007 to 2015, 19 women belonging to UPM coordinated 20 projects. Worthy of note was 2016 calls, when one woman aged 65 coordinated three different international projects. The participation of UPM as a partner, headed by women as principal investigators, was more noticeable from 2007 to 2016: 94 women led 130 actions.

\section{Innovation activities: patents, software licenses, and University-Industry Chairs}

Figure 8a depicts the overall contribution of women $v s$. men in patents at UPM, showing a raising tendency from $2008(7 / 93, \%)$ to 2016 (19/81, \%). Further analysis into UPM's areas revealed that only three out of five fields exhibited representative data related to patents. Figure $8 \mathrm{~b}$ displays the female participation for ICTs, where the average percentage of women was $18 \%$ for the period 2007-2015, followed by a sharp increase in 2016, with $36 \%$ female participation in patents. Supplementary analysis of this data showed that only four women patented in ICTs in 2016, each of them with two patents. On the other hand, Industrial Technologies (see Fig. 8c) held the lowest participation of women in patenting: only $6 \%$ on average in the period under review. Finally, Fig. 8d depicts the situation in Civil and Building Technologies; although gender balance was about to be reached in 2011 (37/63, $\%$ ), the arithmetic mean in 2014-2016 year range was 20\% for women.

The participation of women in software licenses at UPM is depicted in Fig. 9. Figure 9a shows the overall contribution in the university. It displays an upward trend from 2010 to 2012, when gender balance was achieved (53\% female and $47 \%$ male), a strong decrease afterwards, followed by a steady state from 2013 to 2015 (34\%) and a marked decline in 2016 (21\%). The main contribution to this activity was made by ICTs (see Fig. 9b), where the general trend was the same as explained above for the overall UPM data. Nevertheless, in ICTs, the differences within male and female percentages were wider than those found in UPM global records, finding much more favourable outcomes for women than for men (70\% women in 2012, and 42\% women on average from 2013 to 2015), although in 2016 a sharp decrease was also encountered (down to $20 \%$ ).

Lastly, UPM's Industry-University Chairs fall within the innovation activities, as they constitute a mean to establish a strategic and long term partnership between companies and the university, to carry out educational actions, research, or transfer of knowledge jointly. The proportion of women holding an UPM's Industry-University Chair remained stable from 2007 onwards (15\% on average, as depicted in Fig. 10). The low involvement of women was consistent with the percentage of female researchers in the business sector, which is less than $25 \%$ in most countries (EC 2015, 2017).

\section{Management and executive positions}

When power or decision-making positions at UPM's research structures, groups and centres, were analysed, the gender inequality was very noticeable. Positions such as Rector, Vice-Rector, Director of Research Centre and Head of Department were often held by men. The results presented in Fig. 11a show that Principal Investigators or Group Leaders of UPM research groups were men in majority, but a female growing tendency was observed in the last 10 years, from $12 \%$ in 2008 to $20 \%$ women in 2016 . When the same 
(a)

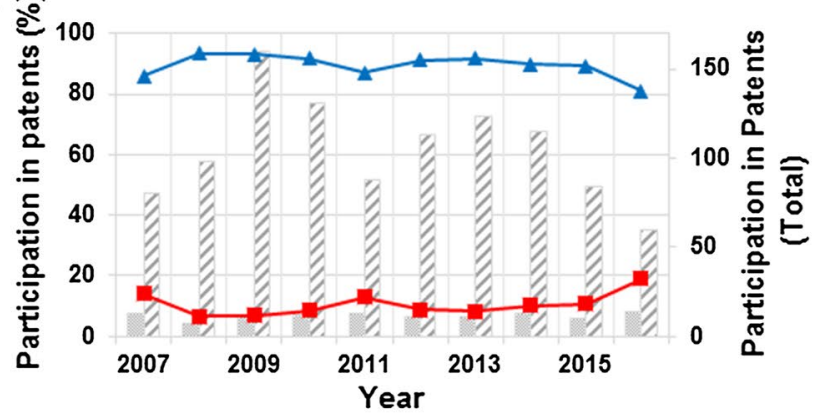

(b)

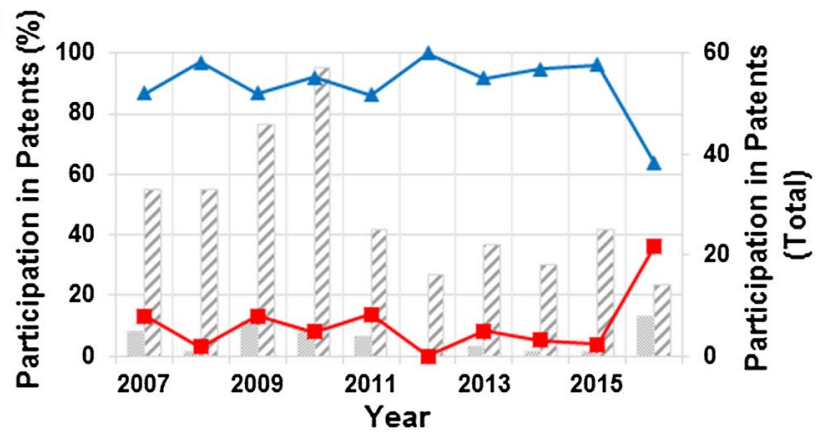

(c)

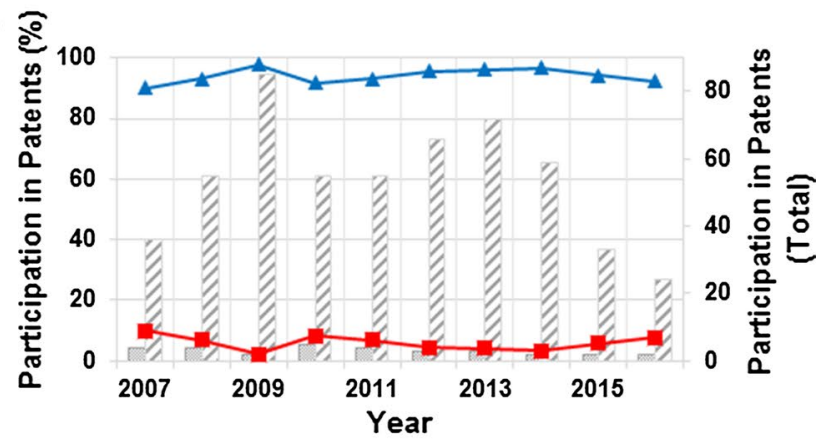

(d)

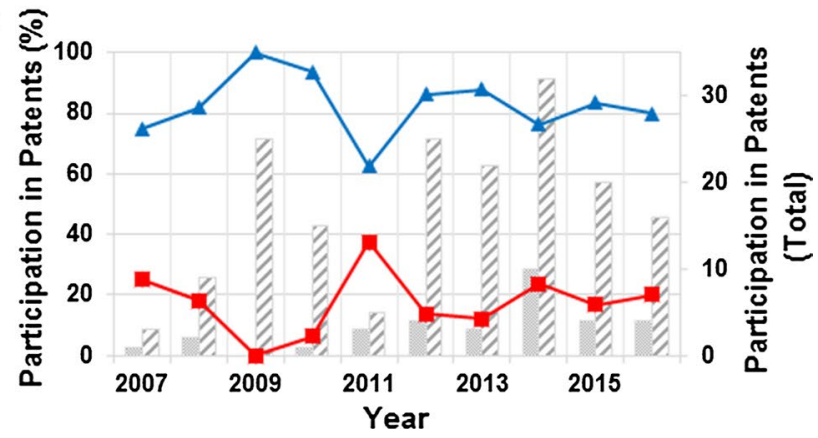


४ Fig. 8 Participation in patents at UPM, by gender: a UPM; b ICTs; c Industrial Technologies; and d Civil and Building Technologies. Filled triangle, Men (\%); filled square, Women (\%); line square, Men $(n)$; dotted square, Women $(n)$

Fig. 9 Participation in software licenses at UPM, by gender: a UPM; and b ICTs. Filled triangle, Men (\%); filled square, Women (\%); line square, Men $(n)$; dotted square, Women $(n)$
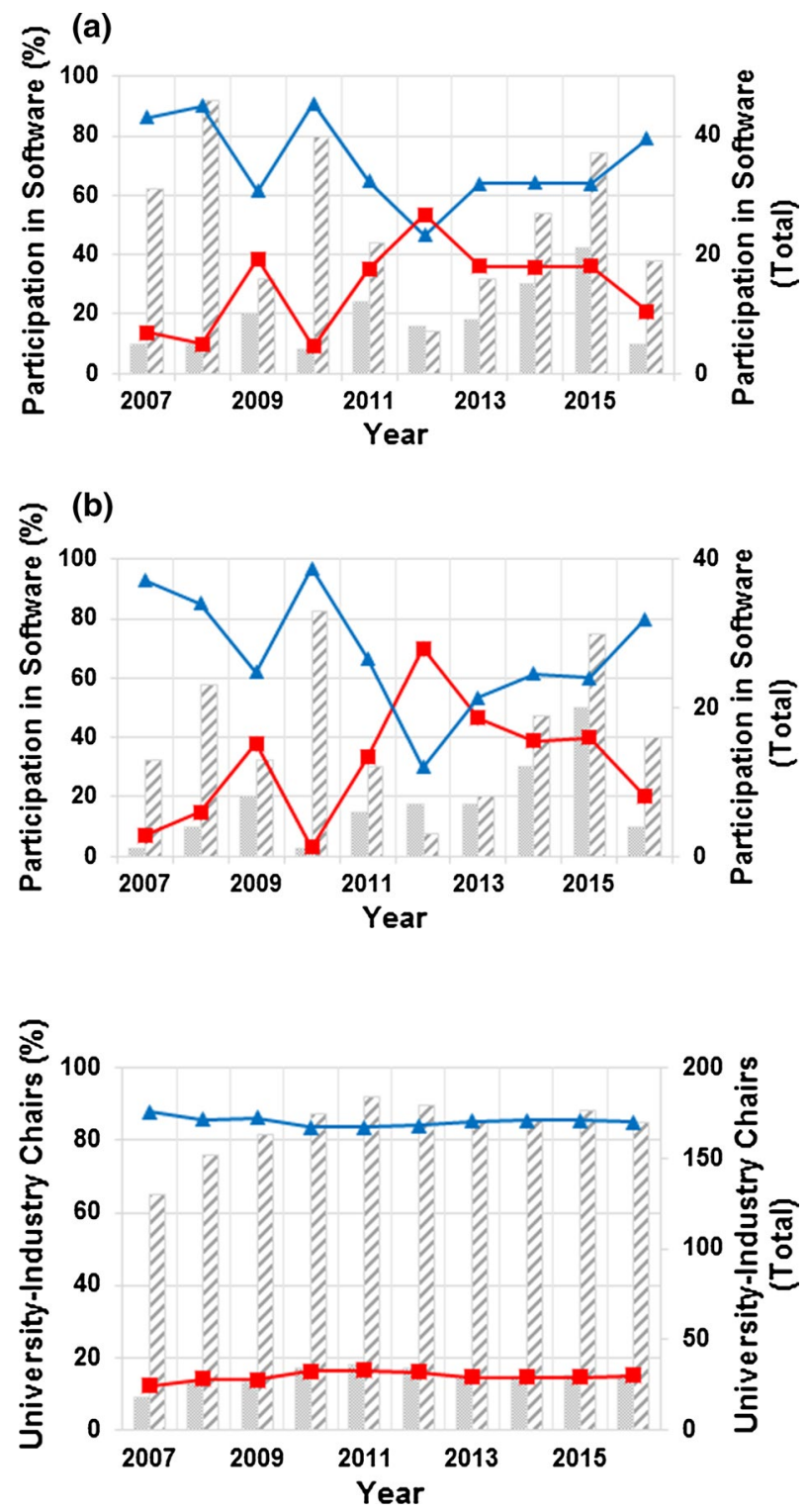

Fig. 10 Participation in UPM's University-Industry Chairs, by gender. Filled triangle, Men (\%); filled square, Women (\%); line square, Men $(n)$; dotted square, Women $(n)$ 
Fig. 11 Principal Investigators of research groups at UPM, by gender: a UPM's groups; b "Top 50" UPM's groups. Filled triangle, Men (\%); filled square, Women $(\%)$; line square, Men $(n)$; dotted square, Women $(n)$

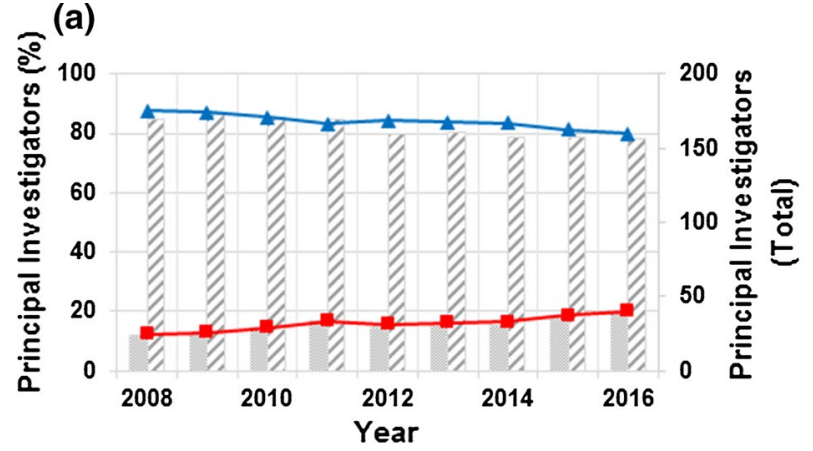

(b)

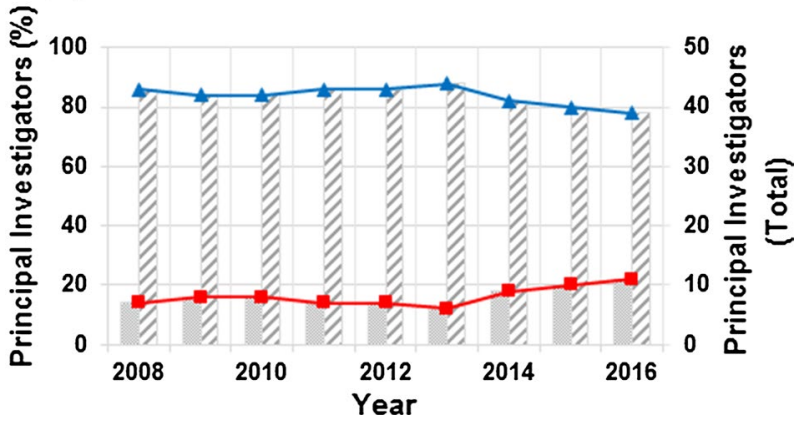

At present, UPM has 20 research centres and institutes, covering different disciplines such as automation, computing and robotics, solar energy, nuclear energy, microelectronics and nanofabrication, transportation, advanced materials, biotechnology and biomedicine, among others. Fig. A1a (see Electronic Supplementary Material) depicts the participation of women in direction of research centres and institutes, which might be considered as an executive position. This figure reached 8\% on average (from 2007 to 2016), attaining values of 15\% in the period 2009-2011. On the other hand, Fig A1b (see Electronic Supplementary Material) shows the participation of women in the UPM Governing Council; the mean value was $15 \%$ for the time range 2007-2016, reaching a maximum 20\% during 2009 and 2010. When analysing the composition of the Senate of the UPM in 2016, the lecturing and research staff was represented by $22 \%$ women, which was lower than the female representation coming from the administrative staff (43\%) and the students (37\%).

A downward trend is found when referring to the composition of the UPM Doctorate Commission, composed by the deputy directors for doctorate studies of UPM schools. In fact, the percentage of women who belong to the Doctorate Commission reached $35 \%$ from academic course 2013-2014 onwards and then dropped down to 26\% in 2016-2017.

\section{Opinion survey and "gap" analysis}

The objective data extracted from UPM internal databases offered a thought-provoking account of the persistent gender inequalities in the UPM, as a descriptive case approach 
providing interesting and valuable insights into differences in women's and men's representation at different position levels and activities.

To this end, an opinion survey and a "gap" analysis were employed to evaluate the underlying mechanisms reproducing inequalities and to demonstrate career paths and working conditions, as well as to add a qualitative investigation to this research. The participation data of the survey is presented in Table 6.

Among the 40 criteria of the European Charter \& Code of Conduct for the Recruitment of Researchers (See footnote 2), the following ones were analysed in this research: 10. Non-discrimination, 12. Recruitment, 13. Recruitment (Code), 14. Selection (Code), 15. Transparency (Code), 16. Judging merit (Code), 21. Post-doctoral appointments (Code), 24. Working conditions (Code), 25. Stability and permanence of employment, 27. Gender balance, 28. Career development, and 32. Co-authorship. The selected criteria were chosen for their ability to give a response to the results of the descriptive statistics. All of them were perceived as fully implemented, except for criteria 25 and 28, which resulted to be insufficiently implemented at UPM. Moreover, all of them were considered important by the UPM researchers, thus all qualifications were ca. 3.5.

As a general rule, no significant differences between women and men were observed as well as among different professional groups. Female researchers manifested a poorer perceived level of implementation in criteria 24, 25, 27 and 28. Besides, Other Technologies research staff and R2 researchers also perceived a minor level of implementation compared to their counterparts.

To begin with, "Non-discrimination" criteria was perceived as "fully implemented" (88\%) and important (3.8) by the UPM researchers. Nevertheless, comments and suggestions indicated that discrimination was still present in UPM: "Discrimination on the basis of sex, age, social status and disability still occurs" (man), "There are still social biases and prejudices that encourage self-censorship when it comes to demanding equal conditions" (man). It was noticeable that the most critical comments came from men.

Criteria 12 and 13 ("Recruitment" and "Recruitment (Code)") were identified as "almost but not fully implemented" (62\% in both cases), and important (3.5 in both cases).

Table 6 Participation data for the opinion survey

\begin{tabular}{lrr}
\hline & $n$ total & Sample \\
\hline Professional category & 2366 & \\
R1 & 312 & 270 \\
R2 & 1346 & 87 \\
R3 & 335 & 242 \\
R4 & & 73 \\
Gender & 3068 & \\
Male & 1290 & 454 \\
Female & & 218 \\
Technological area & 1104 & \\
ICTs & 708 & 244 \\
Agroforestry & 1152 & 128 \\
Industrial & 1213 & 157 \\
Building & 173 & 123 \\
Other & & 20 \\
\hline
\end{tabular}

n total, population; sample, respondents 
A wide representation of the respondents indicated that " $a$ closed/inbreeding system" was present at UPM when recruiting. Moreover, re-start career schemes were not implemented and the difficulty in recruiting young researchers was mainly due to budgetary constraints. "The high degree of inbreeding ... limits the recruitment of new talented researchers" (man), "It is difficult to return to or access to a researcher/teacher position from outside of this system" (woman).

"Selection (Code)" was perceived as "almost but not fully implemented" (57\%) and important (3.4) by the respondents. Most of the participants commented again on the "closed/inbreeding system". Some observations included: "Gender balance is difficult to achieve in our institution due to the lowest number of women in all categories" (man), "The right balance is ... to hire the best qualified people, the proportion should not depend on gender"(man), "Implement control mechanisms to ensure the quality and impartiality of the selection committees" (woman).

"Transparency" was also perceived as "almost but not fully implemented" (62\%) and important (3.5). Researchers commented that selection and recruitment processes were not usually transparent and that the candidates did not received an actual feedback: "I consider that selection criteria and career development perspectives are not properly reported" (woman), "Career perspectives are sometimes not fully explained to the candidates" (man).

Following the analysis, "Judging merit" was perceived as "almost but not fully implemented" (61\%) and important (3.6). Almost all researchers agreed on the importance of bibliometric indices (more specifically, JCR journals), which were not properly balanced within a wider range of evaluation criteria, such as teaching or supervision: "Evaluations place a high value on indexed publications" (woman), "There is a very large imbalance between the quantitative and the qualitative assessment of merits" (man), "There is a strong bias towards bibliometric data: number of papers, and impact factor of them" (man).

"Post-doctoral appointments" were perceived as "almost but not fully implemented" (60\%) and important (3.4). "In many cases, postdoctoral researchers with a good track record have not career opportunities because of the lack of funding" (men), "Long-term career prospects of pre-doctoral and post-doctoral researchers are scarce, due to the lack of positions" (women), "Developing a research career at university is really difficult. Postdoctoral status is not temporary, it is permanent... great uncertainty, with a very low salary" (woman), "Postdoctoral recruitment is almost always based in money from research projects, there are not institutional recruitments" (man).

Researchers perceived "Working conditions" criterion as "fully implemented" (69\%) in UPM, and it was also considered as important (3.7). Contrariwise, both male and female researchers agreed in the lack of reconciliation between family and working life: “... Research, teaching and management, making it difficult to reconcile family and working life" (man), "Teaching loads ... are too high to carry out quality research. There are not mechanisms to protect the reconciliation between family and working life" (woman), "Although I have three children, I have had to teach from 9 a.m. to 9 p.m. Family reconciliation is a chimera" (man), "Reconciliation with family life in the preschool period is very difficult" (woman).

Conversely, "Stability and permanence of employment" was perceived as "insufficiently implemented" (37\%) and important (3.7). The vast majority of the researchers observed differences in the stability and permanence: R1 and R2 staff had a temporary contract, whereas R3 and R4 hold a permanent position. "There are many temporary contracts without future prospects. There is a lack of funds to link contracts to provide stability to the researcher" (man), "Most researchers are hired on a temporary basis with 
no hope of continuing in the long term" (man), "Unstable contracts of short duration and with a very low salary are made without taking into account the special conditions of each highly-skilled researcher" (woman), "As a researcher, there is no stability or permanence of employment, only 2-3 years contract, then looking for another job. Actually, this is an important problem, not only at the level of the institution but at a national level" (woman).

On the other hand, "Gender balance" was observed as "fully implemented" (68\%) and important (3.3). But respondents were aware of the underrepresentation of women in STEAM fields: "There is still a minority of women in engineering. It will be progressively corrected" (man), "Large proportion of men in engineering and architecture studies" (woman), "The proportion of women in ... the university, although higher than years ago, is still significantly lower" (man).

When "Career development" criterion was analysed, researchers perceived it as "insufficiently implemented" (39\%) but important (3.5). Almost all researchers accorded that career development plans were not implemented in UPM and that mentorship would be necessary, not only to define a professional research career, but also to improve employment opportunities: "There is no career projection, primarily due to lack of financing and permanent positions" (man), "There is major insecurity in the professional future, and no mentoring takes place to reduce it" (woman).

Finally, "Co-authorship" was perceived as "fully implemented" (75\%) and important (3.6) by the interviewees. It is worth noting that the majority of the comments on this topic came from male researchers: "Individual publications are evaluated preferably, and if coauthorship, the order of authors" (man), "There is no official regulation of co-authorships, other than good scientific ethics, which are unfortunately not always employed" (man).

\section{Discussion}

The position of the women in STEAM in Spain was previously studied in a comprehensive document presented in 2011 (MINECO 2011), gathering information about gender policies in science and technology, gender differences in scientific education and careers, and the role of the institutions. Empirical evidence available on gender disparities in these areas, and the role played by the institutions that control universities and research centres was also presented. Moreover, the family life of the people working in STEAM in relation to gender differences was analysed. The report stablished a roadmap to be followed to achieve a clearer and deeper understanding of the reasons behind the gender inequalities found.

Previous work on gender statistics at UPM (Sánchez de Madariaga 2013; García-Maroto 2016) was done within the framework of TRIGGER project (project ID: 611034), funded under Seventh Framework Programme (FP7). This publication offered an extensive study of the situation of the women at this university devoted to engineering and architecture. It built on a compilation of data covering the period 2003-2009, presenting graphs that displayed the distribution of students by gender and level of education (undergraduates, graduates, $\mathrm{PhD}$ students and $\mathrm{PhD}$ graduates), the typical academic career at UPM, the participation of women in administrative staff and in decision-making bodies, and some data about projects and funding.

The data analysed in the aforementioned works (MINECO 2011; Sánchez de Madariaga 2013; García-Maroto 2016) concluded that the percentage of women in engineering and some experimental sciences was ca. $30 \%$. However, these documents are merely descriptive and the reasons for such imbalance were not further delved. 
It is well known that higher education acts as a modulator on gender inequalities in the labour market and in certain economic and social scopes (Pastor et al. 2016). Although women are majority in the Spanish universities [55\% on average in academic year 2016-217, according to the Ministry of Education and Vocational Training (See footnote 3 )], they only represented $25 \%$ of the engineering and architecture students, resulting in a low participation of women in doctoral studies related directly with these disciplines, as described before in "Results" section.

Previous studies were carried out to analyse gender issues in the preparation, supervision and defence of $\mathrm{PhD}$ theses in Spanish universities, covering the period 1990-2004 (Villarroya et al. 2008). The ratio of female to male $\mathrm{PhD}$ students in engineering areas was in line with our findings (23/77, female/male, $\%$ ), and gender imbalance among the thesis advisors was even larger (15\% women vs. $82 \%$ men, and $3 \%$ mixed, on average). Likewise, gender inequality was present in $\mathrm{PhD}$ committees, with a repeated predominance of male members.

Academic career typically starts with a PhD completion, thus the analysis by gender of $\mathrm{PhD}$ enrolment and $\mathrm{PhD}$ thesis defence may be a good indicator of the future participation of women in research and innovation activities. In theory, the more women awarded with a $\mathrm{PhD}$ degree, the more women that could apply for a permanent position in academia (personal docente e investigador, PDI, lecturing and research staff). That means the gender gap would disappear when sufficient women will attain their PhD degrees with respect to male $\mathrm{PhD}$ graduates, if other causes of gender imbalance would not be present.

In view of the above mentioned results dealing with "PhD enrolment and defence" (see Figs. 1 and 2), the question that now arises is: What are the main causes of female underrepresentation in doctorate studies? The original and primal reason is the enduring low ratio of women enrolled in the engineering and architecture fields in Bachelor and Master Degrees, where the sociocultural factors, listed in the Introduction section, outweigh the historic ones nowadays. As a consequence of this, many women feel that better-paid jobs, and hence executive and decision-making positions, are effectively barred to them, and that it is virtually impossible to access or apply for such working positions, as these jobs come from the technological sector, especially ICTs (Computer Science, Software Engineering, Artificial Intelligence, Big Data and Telecommunications Engineering, amongst others).

"PhD supervision" data indicated that female $\mathrm{PhD}$ students were mostly matched with a male $\mathrm{PhD}$ advisor (see Fig. 3). Some studies suggested that this circumstance could contribute to a higher women's scientific careers drop-out rate after completing the doctorate. One of the reasons of the early academic career leaving might be attributed to the fact that $\mathrm{PhD}$ researchers are less productive when working with an advisor of the opposite gender, as well as to the preference for working with an advisor of the same gender (Gaule and Piacentini 2017). This theory was also supported by Villarroya et al. (2008) and co-workers when studying the Spanish case, as they also concluded that the gender of the PhD student is clearly concomitant to the gender of the supervisor, mainly male in the UPM case. Moreover, they hold that the gender of the supervisor and doctoral student are decisive in the choice of the gender of the members of the $\mathrm{PhD}$ thesis committees, hence mostly men.

On the other hand, the low representation of female postdoctoral researchers, depicted in Fig. 4, might be interpreted as one of the initial phases of the progressive loss of female talent in the career. Some authors have proposed a model based on three main causes to explain this occurrence (Stack 2004; Borrego et al. 2010; Albert et al. 2016b; Cervia and Biancheri 2017; Hughes et al. 2017): 
1. "Leaky pipeline" model to describe the biased recruitment and career access, as well as the gender gap in research productivity; that is, the number of women that leave the academic career just after $\mathrm{PhD}$ graduation is higher than the number of men.

2. Internal organisational procedures, which exclude women from career advancement in academia ("inbreeding" or closed system).

3. Work-life balance and reconciliation between private and professional life; consequently academic and wife/mother roles are perceived as mutually exclusive and lead to "the productivity puzzle" pattern, attributed to young women being more involved in child bearing and family rearing.

These events might have two negative consequences on junior female academics in Spain. The first consideration is related to the "international postdoctoral mobility", as young Spanish $\mathrm{PhD}$ graduates usually spend periods of time (typically 2 years) in research centres or universities abroad, as a part of their professional career. Competitive Spanish programmes "Juan de la Cierva" and "Ramón y Cajal" assess very positively the participation in international research, and this is also a requirement in public calls for the permanent recruitment of academics and scientists. The second deals with the evaluation and assessment of researchers, which are stricter after the Spanish legislative reform LOU entered into force.

There is empirical data proving that Spanish female academics publish less than men regardless the age (MINECO 2011), although the difference is even more pronounced in young researchers up to the age of 40 , coinciding with the age for maternity. The lack of international experience and postdoctoral secondments, together with the lower scientific and technical production, in comparison with their male counterparts, provide unequal curricula and then reduced opportunities when applying for a permanent job. Similar patterns were found when comparing UPM with Norway (Asksnes et al. 2011; Rørstad and Asksnes 2015): young women in engineering and architecture areas published less and contributed to publications with slightly less impact than their male colleagues. As a consequence, the low productivity level of women slowed down their scientific career development.

In EU in general (Lipinsky 2013; EC 2015) and in UPM in particular (Sánchez de Madariaga 2013; García-Maroto 2016), the more senior the academic position is, the fewer women are represented, as depicted in Fig. A2 of the Electronic Supplementary Material. When analysing the lecturing and research staff after a deeper analysis into the five engineering and architecture areas of knowledge of UPM, it was shown that the percentage of women, while low in all areas, exhibited differentiated behaviours for each of them (see Fig. 5). The origin of the high ratio of women in Agroforestry and Environmental Technologies (Fig. 5c) lies in the fact that some STEAM domains, mainly chemistry and biology, both with a strong presence in this area, are traditionally more genderbalanced than those based on mathematics, physics, applied technology and engineering (Cheryan et al. 2017). On the other hand, the low percentage of female lecturing and research staff found in Industrial Technologies (Fig. 5d) was due to the circumstance that the engineering schools included in this area have traditionally presented an overwhelming presence of men (undergraduates, alumni and staff).

Special mention deserves Civil and Building Technologies. Results found in Fig. 5e might be a result of the event that, over the past 25 years, the number of women enrolled in these disciplines, especially Architecture, showed a steady and significant increase attaining gender balance in the late 1990s (43\% women on average in Spain, from 
academic course 1998-1999 onwards, according to the Spanish College of Architects). Finally, one of the reasons of the tendency for Other Technologies (Fig. 5f) was the attachment of the School of Fashion Design to the UPM. In this school, the proportion of female/male lecturing and research staff was gender-balanced, which contributed positively to enhance the ratio of women in this area.

In view of the analyses, it is reasonable to believe that the involvement of women in research, innovation and doctoral activities will be less meaningful than in the case of men, on an objective basis.

As UPM focuses on engineering and architecture, it has a long tradition of exploitation and commercialization of research technologies, as well as a proven track record in collaboration with companies, not only in scientific and engineering research but also in technological innovation. Innovation is difficult to measure at the individual or personal level, because this contribution is not recognized yet as a merit for promotion in academic career in Spain. But the analysis of patents and software registration offers a feasible way to evaluate and assess the involvement of women in this area, while not all innovations are usually patented or registered.

In general, it is remarkable that the ratio of female researchers taking part in innovation activities (mean value 12\%, Fig. 8) was lower than the average proportion of women belonging to the lecturing and research staff (24\%, Fig. 5). In fact, there is a perception that the gender gap in patenting is much more noticeable than the gender gap in other activities, reflecting not only gender inequality but also an unproductive use of the female innovation capabilities.

According to the Spanish Patent and Trademark Office ${ }^{4}$ (OEPM), patenting also entails high economic expenses: it is time-consuming, delays publication, requires specific knowledge and expertise, needs legal support, and causes uncertainties. These details give researchers little motivation to patent their discoveries, and then to find a way to license them to an interested party, especially if their research group was not a UPM's "Top 50" one, that is, those 50 groups that were in the leading positions when ranked by scientific output and performance (there are 197 consolidated research groups in UPM). Moreover, and in accordance to Figs. 7 and 11, the ratio of women at UPM leading a research group and having the economic potential (projects and budget) to patent with guarantees was very low, as set out in the statistics presented in the previous and next sections. Actually, further analysis of the patents registered by the UPM's "Top 50" groups in the last years (2014, 2015 and 2016), also revealed that the participation of women was very low (11\%), but rather in line with the general trend at UPM (12\%).

There are other cultural reasons to explain the pronounced gender imbalance when patenting. Hunt et al. (2013) stated that women and men perceived the development of innovation from a different point of view, leading to an unbalanced participation by gender in these activities. For their part, Okoń-Horodyńska et al. (2016) and co-workers concluded that, in general, women believed that the capability to make decisions was very important in patenting, while men thought that it was the acquired knowledge and the continuous learning which played a determining and decisive position in this activity.

Analysing the feedback provided by the opinion survey, the comments and viewpoints of the lecturing and research staff passed information to unveil the underlying mechanisms of the low participation of women in UPM. Admittedly, some of the main

${ }^{4}$ https://www.oepm.es/en/index.html. 
causes of the severe underrepresentation of women are linked to the Spanish regulations in force, the negligible replacement rates and the absence of professional continuity. These included the lack of transparency in recruitment and selection processes (perhaps accompanied by a persistent "closed/inbreeding system", as described previously by Villarroya and co-workers), some discrimination by gender and age, and the deficiency of development plans and mentorship to advance in the professional career. Nevertheless, it is significant that a large number of interviewees did not believed in the "positive discrimination" code, but in the principle of recruiting the best-qualified candidate.

Summarizing, there are several objective facts that led to the stubborn underrepresentation of women in academia (Gafni and Siniver 2015; Vázquez-Cupeiro and Elston 2006; Hughes et al. 2017): the historical biasing, the intrinsic gender differences and the socially created ones, the "inbreeding" or closed system, the perceived incompatibility between motherhood and career advancement, and the delayed policies.

The questions posed in the Introduction section have also found explanations based on actual UPM objective data. Generally speaking, there has been a slightly increase in the proportion of women in doctorate, research, innovation, and management activities at UPM in the 2006-2016 period. Men took less time to complete their PhD degree than women, while the proportion of women that defended their doctoral theses was higher than their male counterparts. The success rate when applying for an international project was not gender-biased, but national research projects calls favoured men more. The percentage of women as international projects coordinators was $27 \%$, and $\mathrm{PhD}$ advisors only represented the $10 \%$ of the total, so they should be not regarded as relatable role models.

In the light of the above qualitative analysis, Spanish gender policies from the early 80s onwards have also had a direct impact in the low representation of women in UPM in the 2006-2016 decade, according to the data analysed. Zufiaurre and co-workers (2010) provided an overview of national policy-making to explore the impact of governments and governance on gender policy in Spain from 1983 to 2010. New legislation and actions to promote gender equality were initiated and coordinated from the Spanish government from 2004 onwards. However, the economic crisis that affected severely Spain up to 2013, has led to a growth in inequality, which has revealed the weaknesses and vulnerabilities of the adopted instruments, the social aids, and the institutional structures in former years; that is, the collective reality has not changed significantly, even experiencing a setback. The elimination of the Spanish Ministry of Gender Equality (2008-2010), the persistence of traditional roles and stereotypes about the responsibilities and duties of women and men in the family and in the society, and the low participation of women in decision-making positions as femenine role models, are some of the negative and undesirable consequences of the policies of gender equality in Spain from 2010 onwards (Salazar Benítez 2016).

To understand this fact and the factors which cause it, several surveys had been carried out to examine the interest of Spanish high school students to continue their studies for a particular degree, and the reasons for this choice by gender. When focusing on the students who wish to study engineering and architecture, significant differences between boys and girls were observed when expressing the reason for the choice: the percentage of boys (19.7\%) that was interested in these studies was higher than the percentage of girls $(6.2 \%)$ (Navarro-Guzmán and Casero-Martínez 2012). On the other hand, Moreno and co-workers presented the results of a study carried out in the "Escuela Politécnica Superior" of Universidad Carlos III de Madrid (UC3 M), where a survey was conducted regarding student motivation for choosing an ICT degree. Results showed that the two main reasons were interest in mathematics and labour opportunities (Moreno et al. 2014). 
The low replacement rates given by the Spanish and regional governments, which was almost nil from 2012 up until the present, was another reason for concern. This has particularly serious effects in the average age of the lecturing and research staff (53 years old on average in UPM), and in the generational replacement.

The lack of professional continuity and funds after obtaining a $\mathrm{PhD}$, as well as the difficulties to obtain a competitive post-doctoral contract funded by the UE, the Spanish or regional governments, were other causes of the loss of talent. The major concern expressed by the vast majority of the UPM respondents was with respect to the lack of career development opportunities following doctoral studies: this was the main reason of dropping from the research career. It is remarkable to consider that, if the academic career in Spain is not easy and straightforward, the mean time to obtain a permanent position varies between 10 and 15 years, and there is no possibility of reconciliation between professional and personal life, most women (and, by extension, men) decide to drop off the academic career after completing their $\mathrm{PhD}$ and develop their professional vocations in the private sector.

Finally, the evaluation systems and protocols to obtain a permanent position in Spanish academia are very demanding from 2007 onwards, when the Royal Decree 1312/2007 came into force, establishing national accreditation for access to academic tenured posts. The number of publications as first and/or unique author in prestigious journals is the major merit to evaluate. This issue, along with the large number of teaching and managing hours, make this profession incompatible with the reconciliation between family and work, according to both female and male respondents.

At this point, the family reconciliation is not a concern confined to engineering and architecture fields and academia, and it should not be regarded as a major source of the women underrepresentation in UPM but a generalized social problem in Spain. In fact, it is important to highlight that the number of male lecturing and research staff that request a period of leave of absence to care for children was increasing in UPM in the last years.

By way of comparison, Spanish practicing physicians have achieved gender balance (more than $65 \%$ of students are women) meaning that in a few years females will represent a clear majority within the profession. Difficulties to reconcile are clearly evident in this profession, thus ca. $60 \%$ physicians admitted greater difficulty in reconciling working and family life: the lack of flexibility, arduous undergraduate and postgraduate training programmes, the pressure of working in a competitive service, the long and variable hours of work required in medical practice, particularly in acute hospital service, among others. ${ }^{5}$

\section{Conclusions and policy recommendations}

This paper aimed to offer quantitative and qualitative evidences of the lack of gender balance in engineering and architecture fields, more precisely in the academic area, and contributed to the discussion of the historical, political and socioeconomic causes of the gender inequality found. The study concluded that there was a stubborn and persistent underrepresentation in the participation of women in research, innovation, management and doctoral activities in UPM, although the proportion of women was slightly increasing in some of them.

${ }^{5}$ College of Physicians of Barcelona. 
The data disaggregated by gender and by technological area, as well as their subsequent analysis, provided valuable feedback to the institution, not only to have a clear understanding of the actual situation and to identify the possible underlying causes of male prevalence over women, but also to adopt and implement policies to slow, halt and eventually reverse gender inequality.

Although the causes of the female underrepresentation might initially be strongly linked to gender discrimination, to the existence of a "closed system" in the university, and to the lack of reconciliation between family and work life, a deeper analysis of the qualitative opinion survey showed that the main reasons of the male prevalence in UPM was principally due to the Spanish, and regional government, policies and legislation, the negligible replacement rates, the lack of professional continuity, and the low interest of women in engineering and architecture studies.

Some strategies, or implementation plans, might be based in counteracting the current societal causes of the gender gap, as described as follows:

1. Promotion and visibility of feminine relatable role models (management positions, responsibility roles, teachers and professors).

2. Perception of engineering and architecture as gender-neutral disciplines.

3. Education without discrimination in schools, universities and media.

4. Integration of technological subjects into the school curriculum, from the earliest age, such as computer programming, robotics, engine design, project management, etc.

5. Promotion and adoption of specific measures to achieve maternal and paternal coresponsibility.

6. Implementation of career re-start schemes after parental leave, based on qualitative achievements and scientific/technical potential.

7. Increased investment and new policies in Research and Development.

8. Specific professional opportunities for $\mathrm{PhD}$ graduates either in academia or industry.

9. Increased replacement rates and merit-based recruitment.

10. Development and implementation of equality plans, such as the Gender Equality Plan adopted by the UPM Governing Council on 20th July $2017 .{ }^{6}$

Although it has been amply proved the continued underrepresentation of women occurring at UPM, it is worthy to mention that this is not only a situation at UPM, but also in the majority of Spanish universities, as well as in other institutions abroad (Italy, Norway, Poland, USA, etc.), representing a widespread and global social issue.

This situation shall be corrected in the future, unfortunately in a long time, although the measures adopted by UPM in this sense represent a glimmer of hope. In another key indication of improved prospects, there was a clear tendency towards gender equality in temporary professors hiring, which might lead to a positive effect in the lecturing and research staff gender parity in the foreseeable future.

Acknowledgements This research did not receive any specific grant from funding agencies in the public, commercial, or not-for-profit sectors. We thank Miguel Ángel Lucas and Cristina Merino for extracting the raw data from S2i database; Carmen de Miguel and Valle Hernández for providing all the information about doctoral theses; and Carmen Pérez Nadal, Carmen Gascó and Effectia Consulting for carrying

\footnotetext{
6 http://www.upm.es/sfs/Rectorado/Gerencia/Igualdad/Documentos/PLAN\%20DE\%20IGUALDAD \%20DE\%20G\%C3\%89NERO\%20EN\%20LA\%20UPM.pdf.
} 
out the opinion survey and the "gap" analysis and processing the qualitative data. We also thank Paloma García-Maroto (UPM Equality Unit Director) and Guillermo de la Torre (Observatorio I+D $+i$ UPM Unit) for assistance with the data provided in the Electronic Supplementary Material. We also thank the ViceRectorate for Technology Services for extracting the raw data from AGORA database.

\section{References}

Albert, C., Davia, M. A., \& Legazpe, N. (2016a). Job satisfaction amongst academics: The role of research productivity. Studies in Higher Education, 1, 1. https://doi.org/10.1080/03075079.2016.1255937.

Albert, C., Davia, M. A., \& Legazpe, N. (2016b). Determinants of research productivity in Spanish academia. European Journal of Education, 51(4), 535-549.

Asksnes, D. W., Rørstad, K., Piro, F., \& Sivertsen, G. (2011). Are female researchers less cited? A largescale study of Norwegian scientists. Journal of the American Society for Information Science and Technology, 62(4), 628-636.

Borrego, A., Barrios, M., Villarroya, A., \& Ollé, C. (2010). Scientific output and impact of postdoctoral scientists: A gender perspective. Scientometrics, 83(1), 93-101.

Cervia, S., \& Biancheri, R. (2017). Women in science: The persistence of traditional gender roles. A case study on work-life interface. European Educational Research Journal, 16(2-3), 215-229.

Cheryan, S., Ziegler, A., \& Montoya, A. K. (2017). Why are some STEM fields more gender balanced than others? Psychological Bulletin, 143(1), 1-35.

European Commission. (2015). She figures 2015. Directorate General for Research and Innovation of the European Commission, Brussels, Luxembourg; European Union. https://ec.europa.eu/research/swafs/ pdf/pub_gender_equality/she_figures_2015-final.pdf. Accessed Oct 2017.

European Commission. (2017). Report on equality between women and men in the EU. Directorate General for Justice and Consumers of the European Commission, Brussels, Luxembourg; European Union. https://doi.org/10.2838/52591.

Gafni, D., \& Siniver, E. (2015). Is there a motherhood wage penalty for highly skilled women? The B.E. Journal of Economic Analysis and Policy, 15(3), 1353-1380.

García-Maroto, P. (2016). Women at UPM. Estadísticas de Género en la Universidad Politécnica de Madrid, 2nd Edn. Universidad Politécnica de Madrid, Madrid; Spain. http://www.upm.es/sfs/Recto rado/Gerencia/Igualdad/Documentos/Women\%20at\%20UPM\%20(2\%C2\%AA\%20edici\%C3\%B3n). pdf. Accessed Oct 2017.

Gaule, P., \& Piacentini, M. (2017). An advisor like me? Advisor gender and post-graduate careers in science. IZA Discussion Papers 10828, Institute for the Study of Labor (IZA).

Herrmann, S. D., Adelman, R. M., Bodford, J. E., et al. (2016). The effects of a female role model on academic performance and persistence of women in STEM courses. Basic and Applied Social Psychology, 38(5), 258-268.

Hughes, C. C., Schilt, K., Gorman, B. K., \& Bratter, J. L. (2017). Framing the faculty gender gap: A view from STEM doctoral students. Gender, Work and Organization, 24(4), 398-416.

Hunt, J., Garant, J.-P., Herman, H., \& Munroe, D. J. (2013). Why are women underrepresented amongst patentees? Research Policy, 42(4), 831-843.

Lipinsky, A. (2013). Gender equality policies in public research: Based on a survey among members of the Helsinki group on gender in research and innovation. Directorate General for Research and Innovation of the European Commission, Brussels, Luxembourg; European Union. http://ec.europa.eu/research/ pdf/199627_2014\%202971_rtd_report.pdf. Accessed Oct 2017.

Meschitti, V., \& Smith, H. L. (2017). Does mentoring make a difference for women academics? Evidence from the literature and a guide for future research. Journal of Research in Gender Studies, 7(1), $166-199$.

Moreno, L., González, Y., Segura, I., \& Martínez, P. (2014). Mujeres, Ciencia y Tecnología. Encuesta sobre la percepción de las dificultades de las mujeres en los estudios universitarios técnicos. In XV International conference on human computer interaction (pp. 464-471). Tenerife, Spain.

Navarro-Guzmán, C., \& Casero-Martínez, A. (2012). Analysis of gender differences in degree choice. Estudios sobre Educación, 22, 115-132.

Nimmesgern, H. (2016). Why are women underrepresented in STEM fields? Chemistry-A European Journal, 22(11), 3529-3530.

Okoń-Horodyńska, E., Zachorowska-Mazurkiewicz, A., Wisła, R., \& Sierotowicz, T. (2016). Gender, innovative capacity, and the process of innovation: A case of Poland. Economics and Sociology, 9(1), 252-263. 
Ovseiko, P. V., Greenhalgh, T., Adams, P., et al. (2016). A global call for action to include gender in research impact assessment. Health Research Policy and SYSTEMS, 14(1), 50.

Pastor, J. M., Peraita, C., \& Soler, A. (2016). Higher education as modulator of gender inequalities: Evidence of the Spanish case. Higher Education Policy, 29(1), 63-88.

Pérez-Artieda, G., Gubia, E., Barrenechea, E. et al. (2014). Analysis of women enrollment in Engineering programs at the Public University of Navarre. In IEEE Frontiers in education conference (FIE) (pp. 466-473).

Puy, A. (2015). Científicas en Cifras. Women and Science Unit (UMyC), Cabinet of the State Secretariat for Research, Development and Innovation, Spanish Ministry of Economy, Industry and Competitiveness. http://www.idi.mineco.gob.es/stfls/MICINN/Ministerio/FICHEROS/Informe_Cientificas_en_Cifra s_2015_con_Anexo.pdf. Accessed Oct 2017.

Rørstad, K., \& Asksnes, D. W. (2015). Publication rate expressed by age, gender and academic position-A large-scale analysis of Norwegian academic staff. Journal of Informetrics, 9(2), 317-333.

Salazar Benítez, O. (2016). The fragility of gender equality policies in Spain. Social Sciences, 5(2), 17-33.

Sánchez de Madariaga, I. (2013). Women at UPM. Gender Statistics at Universidad Politécnica de Madrid. Fundación General de la Universidad Politécnica de Madrid, Madrid; Spain. http://www.upm.es/sfs/ Rectorado/Gerencia/Igualdad/Documentos/WOMEN\%20at\%20UPM.\%20Informe\%20TRIGGER.pdf. Accessed Oct 2017.

Spanish Ministry of Economy, Industry and Competitiveness (MINECO). (2011). White paper on the position of Women in Science in Spain. Women and Science Unit (UMyC), Cabinet of the State Secretariat for Research, Development and Innovation. http:/www.idi.mineco.gob.es/stfls/MICINN/Ministerio/ FICHEROS/UMYC/WhitePaper_Interactive.pdf. Accessed Oct 2017.

Stack, S. (2004). Gender, children and research productivity. Research in Higher Education, 45(8), 891-920.

Vázquez-Cupeiro, S., \& Elston, M. A. (2006). Gender and academic career trajectories in Spain. From gendered passion to consecration into a Sistema Endogámico? Employee Relations, 28(6), 588-603.

Villarroya, A., Barrios, M., Borrego, A., \& Frías, A. (2008). PhD theses in Spain: A gender study covering the years 1990-2004. Scientometrics, 77(3), 469-483.

Zufiaurre, B., Pellejero Goni, L., \& Weiner, G. (2010). Gender equality and education in Spain: ideology and governance. Education Inquiry, 1(4), 399-414. 